\title{
Toward robust interpretation of low-temperature thermochronometers in magmatic terranes
}

Kendra E. Murray ${ }^{1}$, Jean Braun ${ }^{2,3,4}$, and Peter W. Reiners ${ }^{1}$

${ }^{1}$ Department of Geosciences, University of Arizona, 1040 East 4th St., Tucson, Arizona, 85721 USA. ${ }^{2}$ ISTerre, Université Grenoble-Alpes, CNRS, BP 53, Grenoble Cedex 9, France.

${ }^{3}$ Helmholtz Centre Potsdam, GFZ German Research Center for Geosciences, Telegrafenberg Building A27, 14473 Potsdam, Germany. ${ }^{4}$ Institute of Earth and Environmental Science, University of Potsdam, Karl-Liebknecht-Str. 24-25, 14476 Potsdam-Golm, Germany

Corresponding author: Kendra Murray (murrayke@ umich.edu)

*Current address: Department of Earth and Environmental Sciences, University of MichiganAnn Arbor, 1100 North University Ave., Ann Arbor, Michigan, 48109 USA

Key Points:

- Intrusive magmatism may produce important first-order effects on patterns of lowtemperature thermochronometer cooling.

- Analytical approximations and numerical models predict cooling ages in and around crustal plutons in steadily exhuming environments.

- Large plutons emplaced in the middle crust at 10-15 kilometers depth can reset lowtemperature thermochronometers in the upper crust.

This is the author manuscript accepted for publication and has undergone full peer review but has not been through the copyediting, typesetting, pagination and proofreading process, which may lead to differences between this version and the Version of Record. Please cite this article as doi: 10.1029/2018GC007595

This article is protected by copyright. All rights reserved. 


\begin{abstract}
Many regions central to our understanding of tectonics and landscape evolution are active or ancient magmatic terranes, and robust interpretation of low-temperature thermochronologic ages in these settings requires careful attention to the drivers of rock heating and cooling, including magmatism. However, we currently lack a quantitative framework for evaluating the potential role of magmatic cooling, i.e., post-magmatic thermal relaxation, in shaping cooling age patterns in regions with a history of intrusive magmatism. Here, we use analytical approximations and numerical models to characterize how low-temperature thermochronometers document cooling inside and around plutons in steadily exhuming environments. Our models predict that the thermal field the pluton intrudes into, specifically the ambient temperatures relative to the closure temperature of a given thermochronometer, is as important as pluton size and temperature in controlling the pattern and extent of thermochronometer resetting in the country rocks around plutons. We identify one advective and several conductive timescales that govern the relationship between the crystallization and cooling ages inside a pluton. In synthetic vertical age-elevation profiles (AERs), resetting next to plutons results in changes in AER slope that could be misinterpreted as past changes in exhumation rate if the history of magmatism is not accounted for. Finally, we find that large mid-crustal plutons, such as those emplaced at $~ 10-15$ $\mathrm{km}$ depth, can reset the low-temperature thermochronometers far above them in the upper crust - a result with considerable consequences for thermochronology in arcs and regions with a history of magmatic activity that may not have a surface expression.
\end{abstract}

\title{
1 Introduction
}

Igneous rocks are commonly targeted for studies of the timing, rate, and spatial patterns of exhumation because they typically contain abundant accessory minerals useful for lowtemperature thermochronology. Interpreting the thermal histories of currently or formerly magmatically active regions is, however, complicated by transient heating and cooling within and adjacent to igneous bodies; interaction between advective and conductive cooling; and transient changes in the regional geothermal gradient. These complexities are seldom quantified or discussed in studies that rely on low-temperature thermochronologic data, in part because independent constraints on past variation of the geothermal gradient are rare. Although numerical models commonly used to interpret thermochronologic data predict the widely recognized effects of topography, relief change, and/or variations in the exhumation rate on the upper crustal geothermal gradient and cooling age patterns (e.g., Braun, 2003; Ehlers, 2005a), this top-down perspective still attributes rock cooling patterns entirely to exhumation-a common assumption that is one of the most important and rarely addressed limitations of using thermochronology to document exhumation and erosion.

This is of particular concern in many regions central to our current understanding of continental tectonics. In the magmatic arcs of the American Cordillera, for example, landscape evolution studies have used low-temperature thermochronology to infer coupling between 
precipitation and erosion (Reiners et al., 2003); tectonic responses to Pleistocene global climate cooling modulated by glacial erosion (Thomson et al., 2010); and how the development of relief and surface elevation reflect tectonic influences on crustal buoyancy (House et al., 1998). Magmatic cooling can also impact the detrital record. Lovera et al. (1999) present a thermokinetic model and statistical framework for using detrital K-feldspar ${ }^{40} \mathrm{Ar} /{ }^{39} \mathrm{Ar}$ ages to derive the exhumation histories of the eroded Peninsular Ranges batholith. Taking a different approach, Malusà et al. (2011) present a conceptual model for how crystallization ages (zircon U/Pb) and cooling ages (biotite K/Ar, zircon and apatite fission track) should change with stratigraphic level in a basin that archives the unroofing of a volcanic-plutonic complex in the Alps. They report that not accounting for magmatic cooling in the detrital source region can result in apparent geological paradoxes-for example, rapid exhumation in a source terrane contemporaneous with slow sediment accumulation rates in the basin-because thermal relaxation can be misinterpreted as rapid exhumation.

At best, studies of landscape evolution in magmatic terranes use available hightemperature geochronology from locally exposed plutons to argue that magma emplacement happened long enough before exhumation that the cooling ages are unrelated to magmatic thermal relaxation (e.g., Guillaume et al., 2013; Murray et al., 2016; Reiners et al., 2003). However, using the lag time between high-temperature crystallization ages and low-temperature cooling ages to make this case is only valid when there is a framework for identifying what a sufficient lag time is - a framework we currently lack. One objective of our study is to quantitatively evaluate this approach.

Early thermochronology studies discussed the cooling of upper crustal plutons as a function of both magmatic thermal relaxation and exhumation (e.g., Harrison \& Clarke, 1979a) because higher temperature methods-and questions-dominated thermochronology at that time. Harrison and Clark (1979a) were the first to model the cooling of a pluton while accounting for geothermal flux, rock uplift, and radioactive heat production. This offered a quantitative check that the proposed post-magmatic history (Harrison \& Clarke, 1979b) is generally valid, but it explicitly did not seek a best-fit thermal history. Another classic study (Calk \& Naeser, 1973) sampled granitic country rocks immediately adjacent to a small basaltic plug to validate fissiontrack annealing kinetics in accessory minerals.

A few studies have explicitly modeled the thermal effects of upper crustal magmatism on bedrock thermochronometers from regions with a known history of magmatism. Lowtemperature thermochronologic ages locally reset by plutonism are useful for identifying hydrothermal ore deposits (Fu et al., 2010; McInnes et al., 2005). In a study of the timing of Rio Grande rift footwall tilting and exhumation, House and others (2003) evaluate the role of hypothesized mid-crustal plutonism on apatite cooling ages on the rift flanks. They concluded that there was little geologic evidence for a pluton of the size and position required to generate the observed age patterns and therefore attributed the cooling to exhumation. Regional magmatism in South Africa's Karoo basin is thought to be coeval with Gondwana breakup, so 
Brown and others (1994) used simple thermal models of various magmatic processes to quantitatively predict the possible effects on the Karoo sedimentary units, concluding additional processes like magmatic hydrothermal activity likely played a substantial role. In each case, whether magmatic cooling was part of the preferred cooling age interpretation, the potential effects of magmatism on the thermal history of the upper crust were clear and substantial.

Spatial and temporal changes in regional heat flow-commonly attributed to lithospherescale processes-have also been interpreted from low-temperature thermochronologic datasets. For example, cooling age patterns have been attributed to the thermal effects-mostly surface uplift and erosion — of transient slab windows (Guenthner et al., 2010; Guillaume et al., 2013) and hotspots (Taylor \& Fitzgerald, 2011). Alternatively, flat slabs may refrigerate the lithosphere (e.g., the Laramide slab in the Sierra Nevada, Dumitru et al., 1991). These studies present conceptual models of these processes, but with the exception of Roy et al. (2004), they do not quantitatively investigate the thermal effects of the proposed geodynamic processes. Moreover, they do not consider magma migration as an important mechanism for rapid and efficient heat transfer in the upper crust.

In sum, despite the clear sensitivity of low-temperature thermochronometers to nonexhumational cooling (Ehlers, 2005b), few studies-especially those relying on the lowest temperature apatite thermochronometers-address this potential complication when interpreting cooling ages.

This study is motivated by the need to broadly quantify how the thermal effects of plutonism manifest in the low-temperature thermochronologic record. We use analytical and numerical thermal models (Figure 1) to predict temperatures and cooling age patterns around and inside thermal anomalies in the upper crust. Our approach is grounded in Laplace's analytical approximation (Figure 1a) to one-dimensional unsteady heat conduction problem in an infinite region (Turcotte \& Schubert, 2002), which finds the general shape and pattern of heating around an instantaneously emplaced heat source and is useful for predicting the general patterns of cooling age resetting. We also use a modified version of the 3D numerical model Pecube (Braun, 2003; Braun et al., 2011) to solve the heat advection-conduction equation and calculate cooling ages in simple emplacement-exhumation scenarios. This provides a guide for further investigations of the geologic circumstances where magmatic heating and cooling should be considered during cooling age interpretation.

\section{Methodology}

\subsection{Low-temperature thermochronometric systems}

Low-temperature thermochronometers are the only tools available for documenting the thermal history of the upper crust on $10^{6}$ to $10^{8} \mathrm{yr}$ timescales. The commonly used (U-Th)/He and fission-track systems in apatite and zircon rely on the time-dependent radioactive decay of $U$ and Th nuclides and the temperature-dependent retention and/or annealing of their daughter 
products $\left({ }^{4} \mathrm{He}\right.$, fission tracks) in individual crystals. On geologic timescales, the kinetics of the diffusion or annealing of these radiogenic daughter products are commonly described as a thermochronometric system's closure temperature, $T_{C}$ (Dodson, 1973), which is a function of the cooling rate. The (U-Th)/He chronometers in apatite (AHe) and zircon ( $\mathrm{ZHe}$ ) document rock cooling below $\sim 40-80$ and $\sim 140-220{ }^{\circ} \mathrm{C}$, respectively. The fission track chronometers in these minerals (AFT, ZFT) document rock cooling below $\sim 90-120$ and $\sim 220-260{ }^{\circ} \mathrm{C}$, respectively.

\subsection{Modeling}

We use two approaches for modeling the thermal effects of magmatic heating and cooling on thermochronometers (see Table 1 for a summary of abbreviations and model variables). First, we use an analytical approximation of Laplace's solution to one-dimensional unsteady heat conduction problem in an infinite region (Turcotte \& Schubert, 2002) to make simple predictions about the patterns of heating around a pluton instantaneously emplaced into a region of the crust of specific ambient temperature. Then, we use the thermo-kinematic model Pecube (Braun, 2003; Braun et al., 2011) to capture how exhumation rate affects the pattern and magnitude of thermochronometer resetting in and around plutons. Pecube is an established tool for quantitative interpretation of thermochronologic data. It solves the 3D heat transport equation in a crustal block experiencing rock uplift and surface erosion beneath a time-evolving surface topography. It computes the time-temperature histories of particles that move through the calculated thermal structure and computes the resulting cooling ages for a range of thermochronometers. The modifications we made for this study are among many in the continuous development of Pecube as its applications have widened to address how thermochronometers document many tectonic and geomorphic processes (Braun et al., 2011).

In Pecube, we simulate the thermal effects of pluton emplacement by holding a region of the model domain at a constant high temperature for a finite time before letting it cool. In these models, the hot region is a rectangular prism or cube. Relevant parameters include the hot region's holding temperature $\left({ }^{\circ} \mathrm{C}\right)$, its depth $(\mathrm{km})$, its half-width, half-length, and half-height $(\mathrm{km})$, as well as the heating start and stop time (Ma). Between the heating start and stop times, model nodes in the prescribed region are isothermally held. To capture the transient thermal response during this heating event and immediately after, the model time step is adapted to be shorter than the conductive timescale of pluton cooling set by the pluton size.

Other than these modifications, the code is as described in Braun (2003; 2011). The model geometry represents a crustal block. Its dimensions are scaled such that the $\mathrm{x}-\mathrm{y}$ dimensions are $\geq 10$ times the pluton half-width $b_{X Y}$ to ensure that the solution is not influenced by the assumed no-flux boundary conditions on the lateral boundaries. We impose a constant basal temperature that is obtained by assuming a linear $25^{\circ} \mathrm{C} / \mathrm{km}$ geothermal gradient and a given crustal thickness. The initial temperature distribution is obtained by running the model to conductive-advective steady state (given the exhumation rate) prior to pluton emplacement. We also assume a flat topography that does not evolve with time, so we can focus our analysis on the 
effect of the thermal perturbation caused by the pluton alone. In order to observe the bedrock cooling age patterns, after pluton emplacement we impose a total exhumation of 9 or $10 \mathrm{~km}$ in each Pecube simulation, which exhumes all rocks that were shallower than or close to the closure depths of the highest-temperature chronometer we model (the zircon He system) at the time of magmatic activity. The length of each model run, therefore, scales with the exhumation rate. We stack the exhumed material into synthetic cross sections to visualize the results. Pecube model parameters are given in Table 2.

As in many thermochronologic studies, closure temperature $\left(T_{C}\right)$ as defined by Dodson (1973) provides a useful framework here. It is, however, a mathematical description of thermochronometer behavior for monotonic cooling histories that has limited quantitative meaning in rocks reheated by magmatic activity. The use of fixed $T_{C}$ in the $1 \mathrm{D}$ model results presented here is, therefore, a simplification of thermochronometer behavior. Pecube, on the other hand, does not rely on the $T_{C}$ concept, instead solving the full production-diffusion (or annealing) equations to calculate cooling ages given the model-predicted rock thermal histories. We report closure depths $\left(Z_{C}\right)$ in Pecube models set by the imposed constant exhumation rate.

\subsection{Definitions}

We use pluton as a general term to describe a volume of igneous material, but do not intend to imply a particular emplacement mechanism, fraction of melt, or bulk compositionthough as described above, the pluton temperatures we use are most relevant for granitic compositions. We suggest that the cooling age patterns discussed here can be associated with the entire range of igneous bodies, from sills to batholiths. Country rocks are the material outside the pluton, which, for simplicity, we assume have the same physical properties (i.e., thermal diffusivity, density) as the plutonic material.

We present model results as patterns of temperature, $T$, or thermochronologic cooling ages, $\tau$, inside and outside modeled plutons. To compare the model results for different exhumation rates, we compare cooling ages to two other ages that are measurable in the model and, potentially, in nature: (1) the cooling age the rocks would have if not perturbed by magmatism (i.e., the cooling age of country rocks in the landscape far from the pluton; $\tau_{L}$ ) and (2) the crystallization age of the pluton (i.e., the pluton's geochronologic age; $\tau_{X}$ ), which is defined in our models as the time elapsed since the end of isothermal heating.

To examine the pattern of cooling ages affected by magmatic cooling, we normalize $\tau$ by $\tau_{L}$ (for the same thermochronometric system) to get a value $\xi$. Where $\xi=1$, cooling ages are unaffected by magmatic cooling and $\tau=\tau_{L}$. Where $\xi<1$, the cooling ages $\tau$ are younger than $\tau_{L}$ and to some extent document the effect of heating by the pluton. In the country rocks outside of and adjacent to the pluton, we define the resetting aureole to be the part of the thermal aureole where $\xi<1$ for a particular thermochronometric system. We note that in most thermochronologic datasets, intra-sample cooling age reproducibility is commonly $\sim 10 \%$, and therefore in nature, only $\xi$ values of $<0.9$ would be a significant thermochronologic signal. 


\subsection{Simplifying magma body energetics}

Our modeling approach reduces the complex and poorly constrained process of magma emplacement to a simple thermal event. We do not attempt to mimic thermal pulses from individual emplacement events that likely build intrusive complexes and their source regions (Annen, 2011; Annen et al., 2015; Glazner et al., 2004). Nor do we account for the dependence of thermal diffusivity on temperature (Nabelek et al., 2012), the effects of magma or fluid convection within or surrounding the intrusion (Norton \& Knight, 1977; Norton \& Taylor, 1979; Parmentier \& Schedl, 1981), or a particular style of magma emplacement. Although important at some spatial and temporal scales (Jaeger, 1964), these factors present substantial uncertainties and numerical challenges that are beyond the scope of this study. Moreover, at the $>10^{6} \mathrm{yr}$ timescales that thermochronometers document, the thermal effects of many of these processes would effectively smooth out, so our simple models should capture the first-order effects of intrusive systems on the thermal architecture of the upper crust.

Additionally, we are only modeling the pluton's sensible heat and therefore do not directly account for the latent heat of crystallization, which constitutes a considerable fraction of a cooling pluton's total energy. Because the sensible heat is proportional to the temperature difference between the pluton and the country rocks, the latent heat is a larger fraction of the total heat available to raise the temperature of the country rocks in more deeply emplaced magma bodies. For example, for a granitic magma at $750{ }^{\circ} \mathrm{C}$, latent heat is $\sim 25 \%$ of the total if emplaced into $50{ }^{\circ} \mathrm{C}$ country rocks but $\sim 70 \%$ if the country rocks are $650{ }^{\circ} \mathrm{C}$.

In models without a complete mathematical treatment of magma energetics, like ours, it is common to account for latent heat by simply increasing the initial pluton temperature (Calk \& Naeser, 1973; Harrison \& Clarke, 1979a). However, the actual temperatures experienced by the country rocks, and not just the total pluton heat, are important for thermochronology. So instead, in our Pecube models we hold a pluton at a constant temperature of $750{ }^{\circ} \mathrm{C}$ for thousands of years during 'emplacement'. This mimics how latent heat would function as a thermal buffer (Huber et al., 2009) that keeps the pluton hotter for longer than sensible heat alone. The emplacement duration time, along with the pluton and country rock temperatures, controls how much heat is added and therefore has a substantial effect on the extent of thermochronometer resetting. Therefore, we use a conservatively cold pluton temperature $\left(750{ }^{\circ} \mathrm{C}\right)$ because it is below the solidus for most magma compositions. Incrementally constructed magma bodies cool below the magma solidus between injection events in all but rare high-flux scenarios (Annen, 2011). In most simulations, we scale the holding time to the pluton volume because the timeaveraged rate of pluton construction is broadly correlated to total volume (de Saint-Blanquat et al., 2011). We use a rate of $10^{-2} \mathrm{~km}^{3} / \mathrm{Myr}$, slightly faster than the average range observed in compilations of data from a diverse range of igneous body size, composition, and tectonic setting $\left(10^{-1}\right.$ to $10^{-4} \mathrm{~km}^{3} / \mathrm{Myr}$, de Saint-Blanquat et al., 2011).

Although choosing a pluton temperature of $750{ }^{\circ} \mathrm{C}$ is meant to simulate the thermal effects of granitic magmas, the difference between the latent and sensible heat outlined above 
provides a useful scaling relationship relating intrusions of varying temperature (e.g., granite and basalt). To generate the same amount of heat as a granite magma at shallow crustal levels (i.e., country rocks at $25{ }^{\circ} \mathrm{C}$ ) $\sim 33 \%$ less basalt volume is required; for deeper crustal levels (country rocks at $650{ }^{\circ} \mathrm{C}$ ) $\sim 60 \%$ less is required.

\section{Advection and conduction timescales}

Our purpose is to investigate the thermal perturbation caused by the emplacement of a pluton and how it affects the distribution of thermochronometer ages otherwise set by exhumation-driven cooling. For simplicity, we assume a constant exhumation rate in each of our models. The cooling history of a rock inside or in the vicinity of the pluton is governed by the competition between advective (or exhumation-driven) heat transport, conductive cooling through the Earth's surface, and conductive cooling of the pluton. We can measure the efficiency of each process through their respective characteristic timescale. The timescale for conductive cooling of the crust is given by:

$$
\varphi_{C}=\frac{L^{2}}{\kappa}
$$

and the timescale for heat advection by:

$$
\varphi_{A}=\frac{L}{\dot{E}}
$$

where $L$ is a length scale $(\mathrm{km}$, usually the thickness of the crust or of the crustal layer being exhumed), $\dot{E}$ is the exhumation rate $(\mathrm{km} / \mathrm{Myr})$, and $\kappa$ the thermal diffusivity $\left(\mathrm{km}^{2} / \mathrm{Myr}\right)$. The relative efficiency of these two processes can be assessed by the ratio of these two timescales, which defines the so-called Péclet number:

$$
P e=\frac{\varphi_{C}}{\varphi_{A}}=\frac{\dot{E} L}{\kappa}
$$

When $P e \gg>1$, advective transport dominates and there is a strongly depth-dependent geothermal gradient. When $P e<<1$, conductive cooling dominates and the geothermal gradient is quasi-uniform with depth. The timescale for conductive cooling of the pluton is, in turn, given by:

$$
\varphi_{C}^{\text {pluton }} \propto \frac{b^{2}}{\kappa}
$$

where $b$ is the half-width (or radius) of the pluton. The ratio of the pluton conductive timescale to the advection timescale measures how rapidly the pluton cools while being exhumed:

$$
P e^{\text {pluton }}=\frac{\varphi_{C}^{\text {pluton }}}{\varphi_{A}}=\frac{\dot{E} b^{2}}{L \kappa}
$$


The competition between the advection and diffusion of heat also dictates what part of the rock cooling history (magmatic or exhumational) a thermochronometer documents, given that $\dot{E}$ sets the advection timescale (Equation 2), and the pluton size (a length scale) sets a conductive timescale proportional to its half-width, $b$. (Equation 4).

When a $3 \mathrm{D}$ pluton is emplaced into a block with a geothermal gradient, two different pluton dimensions are important length scales (Appendix 1). The conductive cooling timescale at the center of the pluton is set by the pluton thickness in the $\mathrm{Z}$ dimension, because the thickness is parallel to the principal direction of heat conduction toward the cold surface. The cooling timescale in the resetting aureole next to the pluton is set by the pluton's X and Y dimensions. Therefore, in our 3D models we distinguish between the half-width in the $\mathrm{Z}$ dimension $\left(b_{Z}\right)$ and the half-widths in $\mathrm{X}$ and $\mathrm{Y}$ dimensions, which are equal $\left(b_{X Y}\right)$.

\section{$41 D$ analytical approximation}

\subsection{Laplace's solution}

In country rocks adjacent to a pluton, the width of a resetting aureole is a function of the ambient temperature at the depth, $T_{Z}$, and the closure temperature of the thermochronologic system, $T_{C}$. An approximate expression for the width of the resetting aureole as a function of $T_{Z}$ and $T_{C}$ can be derived from Laplace's solution to one-dimensional unsteady heat conduction problem in an infinite region (Turcotte \& Schubert, 2002 Equation 4-157) given by:

$$
T=\frac{1}{2 \sqrt{\pi \kappa t}} \int_{-\infty}^{\infty} \bar{T}\left(y^{\prime}\right) e^{-\left(y-y^{\prime}\right) / 4 \kappa t} d y^{\prime}
$$

where $t$ is time, $c$ is heat capacity, $\rho$ is density, $\kappa$ is thermal diffusivity, $y$ is a horizontal spatial coordinate, and $\bar{T}(y)$ is the initial temperature anomaly from a heat source (Table 1). If we only solve for the temperature in the resetting aureole far from the pluton, $y>>b_{X Y}$, where $b_{X Y}$ is the pluton half-width, we can approximate the pluton as a planar source of heat located at $y$ $=0$ (Figure 1a). The solution gives the temperature-time evolution at a distance $y$ from an instantaneously emplaced heat source:

$$
T(y, t)=T_{Z}+\frac{Q}{2 p c \sqrt{\pi \kappa t}} e^{\frac{-y^{2}}{4 \kappa t}}
$$

where $Q$ is the amount of heat contributed by the pluton:

$$
Q=\rho\left[c\left(T_{P}-T_{Z}\right)+l\right] 2 b_{X Y}
$$

$T_{P}$ is the pluton temperature and $l$ is the latent heat of crystallization (which here we assume is 0). From Equation 7 we can derive the time at which rocks at position $y$ reach their maximum temperature $\left(t_{\max }\right)$ :

$$
t_{\max }(y)=\frac{y^{2}}{2 k}
$$


The peak temperature at that time is:

$$
T_{\max }(y)=T_{Z}+\frac{Q}{\rho c y}\left(\frac{1}{2 \pi e}\right)^{0.5}
$$

By combining equations 8 and 10, we estimate the distance $y$ where $T_{\max }$ equals a temperature of interest, for example, the $T_{C}$ of a thermochronologic system:

$$
y_{\text {max }} \cong\left(\frac{T_{P}-T_{Z}}{T_{C}-T_{Z}}\right)\left(\frac{b_{X Y}}{2}\right)
$$
(Figure 2a).

Rocks within $y_{\max }$-distance of the pluton experienced peak temperatures greater than $T_{C}$

This approximation highlights a principal feature of resetting aureoles: Their width increases exponentially with $T_{Z}$, as $T_{Z}$ approaches the $T_{C}$ of the thermochronologic system of interest (Figure 2a).

\subsection{Schematic cooling age patterns}

Laplace's simple solution highlights two spatial relationships that control whether a country rock's temperature exceeds a thermochronometer's $T_{C}$ as a result of localized heating next to pluton: (1) the rock's depth, or more exactly, it's ambient temperature $T_{Z}$ at the time of magmatism and (2) its proximity to the pluton. All else being equal, these two variables control the shape of the temperature field and therefore the spatial extent of the resetting aureole (Figure 2a, 3a). If we assume a pluton was emplaced into a crustal block where the cooling age pattern prior to magmatism was set by steady and spatially uniform exhumation (e.g., Figure 3b), and that this steady exhumation continued long after magmatism, we can make simple schematic predictions of the horizontal and vertical cooling age patterns that plutonism should produce.

Along horizontal transects (Figure 2a) where $T_{Z}<T_{C}$, the cooling ages range from $\tau=\tau_{X}$ close to the pluton to $\tau \cong \tau_{L}$ far from the pluton, and the width of the thermochronometer resetting aureole is a function of the $T_{Z}$ at the time of magmatism (Figure 2b). At depths where $T_{Z}$ is closer to $T_{C}$, the resetting aureole is wider, and, under our assumption of steadyexhumation, the difference between reset and unreset ages is also smaller (Figure 2b). This is because at the time of magmatism, the cooling ages in rocks where $T_{Z}$ is close to $T_{C}$ are very close to zero (Figure $3 \mathrm{~b}$ ) and so resetting results in a smaller change in age than in rocks where $T_{Z} \ll<T_{C}$. As time passes and these transects progressively exhume, the pluton age $\tau_{X}$ gets older and the difference between $\tau_{X}$ and $\tau_{L}$ decreases until the rocks being exhumed were at $T_{Z}>T_{C}$ at the time of plutonism, had a cooling age of $\tau=0$ at that time, and were therefore unperturbed by pluton heating.

In vertical transects (Figure 3), a pluton's perturbation of the existing age- $T_{Z}$ relationship (Figure $3 b$ ) is a function of the horizontal distance from the pluton (Figure 3c). The vertical thickness of the resetting aureole is greatest in transects closes to the pluton. This resetting 
extends up from rocks where $T_{Z}=T_{C}$ at the time of plutonism. The resetting aureole in a vertical transect manifests as significant kinks in the age- $T_{Z}$ relationship, which is progressively exhumed (Figure 3d) during post-magmatic exhumation.

Several key insights follow from this simple 1D treatment. First, the ambient temperature $T_{Z}$ is as important as pluton size and temperature in controlling the amount of extra heat added to the crust by a pluton and therefore its thermal effect (Equation 7). Second, resetting aureoles for low-temperature thermochronometers with different $T_{C}$ will be nested. The higher $T_{C}$ systems will have narrower aureoles that extend to higher $T_{Z}$ than those with lower $T_{C}$ (Figure $3 \mathrm{a}$ ). Third, in a steadily exhuming landscape with no additional perturbations, if a pluton's crystallization age $\tau_{X}$ is older than the cooling age of the country rocks $\tau_{L}$, then the magnitude of exhumation since pluton emplacement is greater than the depth to the closure temperature, $Z_{C}$, of the thermochronometric system (final panels of Figures 2b, 3d). Finally, in vertical profiles, as would be obtained in nature from a borehole or vertical sampling transect, the resetting aureole manifests as significant changes in the slope of the age- $T_{Z}$ (i.e., age-depth, age-elevation) relationship (Figure 3c,d). Such trends in low-temperature thermochronologic data are commonly used to infer past changes in erosion rate, but here they reflect a history of steady erosion during which exhumation-driven cooling was perturbed by a transient thermal event.

Laplace's approximation has limited utility beyond broadly characterizing the features to expect from thermochronometer resetting around plutons, because it does not include the kinetics that govern how low-temperature thermochronometers respond to temperature change over time. For example, a $T \geq T_{C}$ condition must be long lived in order to fully reset a thermochronometer, and therefore the location of $T_{\max }=T_{C}$ (Figure $3 \mathrm{a}$ ) overestimates the width of thermochronometer resetting aureoles. Next, we use a numerical model that solves the thermochronologic age equations to more robustly explore how low-temperature thermochronometers document interactions between magmatic and exhumation-driven cooling.

\section{Upper-crustal plutons}

Using Pecube, we model several pluton geometries and emplacement depths to examine the effects of heating from a single pluton in the upper crust (Figure 1b-d). We compare cooling age patterns from models where the exhumation rate is set at three different but constant values of $\dot{E}=0.01,0.1$, or $1 \mathrm{~km} / \mathrm{Ma}$. We limit the results presented here to the apatite and zircon $\mathrm{He}$ systems, because they span a representative temperature sensitivity range for low-temperature thermochronometers.

\subsection{Simplest 3D Models}

We first model a tall, narrow pluton (Figure 1b) that resembles the infinite-sheet heat source of Laplace's solution. The crustal block (model domain) is $30 \times 30 \mathrm{~km}^{2}$ by $10 \mathrm{~km}$ thick and has a pluton of dimensions $b_{X Y}=6 \mathrm{~km}$ and $b_{Z}=8 \mathrm{~km}$ kept at $750{ }^{\circ} \mathrm{C}$ for $10 \mathrm{kyr}$. 


\subsubsection{Horizontal transects}

Horizontal cooling age patterns (Figure 4) follow the predictions from Laplace's solution (Figure 2b). Inside and immediately adjacent to the pluton, the cooling ages are approximately equal to the pluton crystallization age $\left(\tau \cong \tau_{X}\right)$. Moving away from the pluton in each transect where $T_{Z}<T_{C}$, we predict the existence of a partially reset zone, where cooling ages are older than the pluton but younger than the landscape cooling age $\left(\tau_{X}<\tau<\tau_{L}\right)$. Farther from the pluton, magmatic cooling did not affect cooling ages, so $\tau=\tau_{L}$ and $\xi=1$.

In order to examine the effects of different exhumation rates, $\dot{E}$, on the cooling age patterns predicted inside and around plutons for two different thermochronometric systems, we have to select comparable horizontal transects from each model (Figure 4). For this, we have to find comparable depths relative to the thermochronometer $T_{C}$ (i.e., Figure 2). Simply normalizing $T_{Z}$ by $T_{C}$ does not account for the possibility of a non-linear geothermal gradient in scenarios with rapid $\dot{E}$ and large $P e$ numbers (Equation 3, Figure 5) and the resulting dependence on the depth of the closure temperature, $Z_{C}$, on $\dot{E}$. The temperature at a depth $z$ for a given $P e$ value is:

$$
T(z)=T_{B} \frac{1-e^{-P e z} / B}{1-e^{-P e}}(12) .
$$

and the depth to the closure temperature is:

$$
z_{C}=-\frac{B}{P e} \ln \left(1-\frac{T_{c}\left(1-e^{-P e}\right)}{T_{B}}\right)
$$

where $B$ is the thickness of the model in the $z$ direction and $T_{B}$ is the temperature at the base of the model. We compare transects from the same $Z / Z_{C}$ (i.e., depth normalized to $Z_{C}$ ) depths:

$$
\frac{Z}{Z_{C}}=\frac{\ln \left(1-\frac{T_{Z}\left(1-e^{-P e}\right)}{T_{B}}\right)}{\ln \left(1-\frac{T_{C}\left(1-e^{-P e}\right)}{T_{B}}\right)}
$$

The transects of normalized cooling age $\xi$ as a function of $y / b_{x y}$ from depths where $Z / Z_{C}$ $=0.25,0.5,0.75,1$, and 1.25 (Figure $4 \mathrm{a}$ ) show the progressive widening of the resetting aureole with increasing $Z / Z_{C}$ (Figure $2 \mathrm{~b}$ ). The maximum width of the resetting aureoles around these plutons is substantially smaller that suggested by Laplace's solution, because fully or partially resetting a thermochronometer requires significant time at temperatures at or exceeding $T_{C}$, not just instantaneously reaching a peak temperature greater than the $T_{C}$ set by $\dot{E}$.

As shown in Figure 4, faster $\dot{E}$ results in wider resetting aureoles. At slow rates (Figure $4 \mathrm{~b}-\mathrm{e})$, the resetting aureoles for both thermochronologic systems are at most $\sim b_{x y}(3 \mathrm{~km})$ wide, with slightly wider aureoles at $0.1 \mathrm{~km} / \mathrm{Myr}$. When $\dot{E}=1 \mathrm{~km} / \mathrm{Myr}$ (Figure $4 \mathrm{f}-\mathrm{g}$ ), the resetting aureole extends as much as $2 b_{x y}$ from the pluton edge. 
Within the pluton, comparing a transect's $Z / Z_{C}$ value to the $\xi$ value $\left(\tau / \tau_{L}\right)$ reveals the effect of $\dot{E}$ on pluton cooling and thereby the cooling ages of plutonic rocks. At shallow depths and in slowly exhumed models (Figure $4 \mathrm{~b}-\mathrm{e}$ ), the $Z / Z_{C}$ value is approximately equal to $\xi$. For example, in the model with $\dot{E}=0.01 \mathrm{~km} / \mathrm{Myr}$ (Figure $4 \mathrm{~b}, \mathrm{c}$ ), the transect from a shallow depth where $Z / Z_{C}=0.25$ has pluton cooling ages that are $25 \%$ of the landscape's background cooling age (i.e., $\xi=0.25$ ) and therefore $\xi=Z / Z_{C}$. This reflects very rapid cooling to below the thermochronometer closure temperatures after emplacement. In deeper transects very close to the closure depth $\left(Z / Z_{C} \sim 1\right.$, Figure 4$)$, the plutonic rocks are hotter than $T_{C}$ for longer because little additional heat is required to maintain $T>T_{C}$. As a result, the pluton cooling age is younger than the cooling age we would predict from rapid post-emplacement cooling to ambient temperatures. Therefore, the normalized age is less than the normalized depth $\left(\xi<Z / Z_{C}\right)$. In models with rapid $\dot{E}$, this effect is magnified and $\xi<Z / Z_{C}$ at much shallower depths (Figure 4f,g). The deviation from $\xi \approx Z / Z_{C}$ is greater for the apatite He results than for the zircon He results (Figure $4 \mathrm{f}, \mathrm{g}$ ).

\subsubsection{Advection and pluton cooling}

Delayed cooling in advection-dominated systems with rapid $\dot{E}$ is predicted by these 3D models. It manifests as a deviation from $Z / Z_{C} \approx \xi$ inside a pluton (Section 5.1.1 and Figure 4f,g) and reflects how advection controls the efficiency of dissipating a transient heat anomaly in the crust.

If the pre-intrusion geothermal gradient is approximately linear because exhumation rates are slow (i.e., $\dot{E}<1$ ), the $Z / Z_{C}$ value is also the ratio between the pluton age and the landscape cooling age $\left(\tau_{X} / \tau_{L}\right)$. Because we defined $\xi=\tau / \tau_{L}$, the ratio between $\xi$ and $Z / Z_{C}$ is also the ratio between the pluton's cooling age and emplacement age:

$$
\frac{\xi}{Z / Z c}=\frac{\tau}{\tau_{X}} \quad(15)
$$

Plutonic rocks that rapidly cooled after emplacement to the ambient $\mathrm{T}$ set by $\dot{E}$ have $\tau \cong \tau_{X}$ and $\xi /\left(Z / Z_{C}\right)=1$, which is why $\xi \approx Z / Z_{C}$ inside the pluton and parts of the resetting aureoles in the slowly exhumed and shallowest transects in Figure 4. If cooling is delayed, then the lag time between the pluton crystallization and cooling is longer, $\tau<\tau_{X}$, and therefore $\xi<$ $Z / Z_{C}$.

We use a simpler 1D conduction-advection model to illustrate this behavior. In Figure 5, we compute the shape of a geothermal gradient (in normalized depth vs. temperature space) set by three different exhumation rates that correspond to $P e$ values of $0.1,1$, and 10 . We perturb these temperature-depth gradients with the same temperature anomaly and predict temperaturedepth profiles at 10 subsequent time steps evenly spaced over the time it takes to advect a point from the center of the model-inside the pluton - to the surface. The amount of time this advection takes scales directly with the $P e$ value; it takes 100 times longer for 10 time steps to elapse in the $P e=0.1$ model than the $P e=10$ model. In contrast, the time it takes for conductive 
relaxation of the pluton is constant. As a result, in slowly advecting models, the system conductively dissipates the heat anomaly introduced by the pluton much more rapidly than it advects it (Figure 5a). Whereas in rapidly advecting models, rocks from a given depth take much longer to cool relative to their exhumation time to the surface (Figure 5c). They potentially remain hotter than $T_{C}$ longer and have smaller $\xi\left(\tau / \tau_{L}\right)$ values.

For lower-temperature thermochronometers, it takes less time for rocks to get from $Z_{C}$ to the surface (i.e., the advection timescale is shorter) and the system has less time to conductively dissipate the pluton heat over that time. This explains why thermochronometers with colder closure temperatures and shallower $Z_{C}$ (i.e., the apatite He system here, Figure $4 b, d, f$ ) are more perturbed $\left(\xi<Z / Z_{C}\right)$ at $\operatorname{rapid} \dot{E}$.

\subsubsection{Vertical profiles}

Examining these results along a vertical cross section (Figure 6) offers a perspective relevant to sampling strategies common in low-temperature thermochronology. Contoured normalized cooling ages $(\xi)$ from a cross section through the model (Figure 6 , left panels) show resetting aureoles widening as $Z$ approaches $Z_{C}$ and the significantly wider resetting aureoles for plutons emplaced in rapidly exhuming scenarios. The difference between $\tau$ and $\tau_{L}$ in vertical profiles at different positions relative to the pluton (Figure 6, middle panels) shows the magnitude of the resetting in Myr. To demonstrate how these age patterns would manifest in a vertical transect, we construct synthetic age-elevation relationships (AERs, Figure 6, right panels). The AERs are for a snapshot in time at the end of the model run, when $9 \mathrm{~km}$ of exhumation has occurred since pluton emplacement. It takes 2 orders of magnitude longer to exhume this thickness of crust when $\dot{\mathrm{E}}=0.01 \mathrm{~km} / \mathrm{Myr}$ than when $\dot{\mathrm{E}}=1 \mathrm{~km} / \mathrm{Myr}$, so the cooling and crystallization ages also vary by orders of magnitude between the models.

As predicted by the Laplace solution (Figure 3), AERs vary as a function of distance from the pluton (Figure 6, right panels). In the plutonic rock at the center of the model, the AER is subvertical at shallow levels where $\tau \cong \tau_{X}$ because $T_{Z}<T_{C}$ at the time of magmatism and the thermochronometers are documenting rapid post-magmatic thermal relaxation. In the plutonic rock emplaced near $T_{Z}=T_{C}$, the lag time between $\tau$ and $\tau_{X}$ is greater and the AER shallows, approaching a slope defined by $\dot{E}$. In the country rocks, an AER slope can be shallow or steep compared to the slope set by $\dot{E}$ and can have three kinks in slope. This is captured best by the zircon He system (Figure 8b, right panels, green, purple, and yellow curves). At shallow levels, the AER slope reflects the background $\dot{E}$ because the rocks are unreset. At hotter $T_{Z}$, the AER slope shallows substantially with increasing partial-resetting; then it steepens to subvertical where fully reset by the pluton heating; and then finally it shallows again at $T_{Z} \gg T_{C}$ to reflect the constant $\dot{E}$. 


\subsubsection{Consequences for age-elevation interpretations}

Slope changes in vertical profile AERs are commonly interpreted as past changes in exhumation rate. AER slopes in resetting aureoles (Figure 6) could be wrongly interpreted as past variability in $\dot{E}$ if not recognized as resulting from magmatic thermal perturbations. In most settings, a vertical crustal section available for sampling is no more than 3-4 km thick. To explore how this may manifest in nature, we calculated the apparent exhumation rate over a onekilometer moving average using cooling ages along each AER to examine the predicted magnitude of this effect inside the pluton and in the country rocks.

Inside the pluton at shallow levels, the subvertical AER reflects rapid thermal relaxation and if interpreted as $\dot{E}$ would overestimate the rate by an order of magnitude or more; greater overestimation would occur in slowly exhuming landscapes. At depths near Zc, the AER shallows and approaches a slope that reflects the actual $\dot{E}$, so the $\dot{E}$ overestimation diminishes in rocks from depths where $T_{Z}$ was close to $T_{C}$. At faster $\dot{E}$, the AER slope inside the pluton doesn't reflect the actual $\dot{E}$ until rocks that were nearly $1 \mathrm{~km}$ deeper than the $Z_{C}$ at the time of magmatism, although $\dot{E}$ is only overestimated by a factor of two in rocks below the $Z_{C}$ in these scenarios. These trends in the plutonic rocks are simple compared to those in the resetting aureoles because $\tau$ cannot be older than $\tau_{X}$.

The AERs within the country rock resetting aureoles change significantly in slope and could result in either over- or under-estimation of $\dot{E}$. Consider a transect at distance $1.67 b_{x y}$ from the pluton center (Figure 6b, purple vertical profiles). At shallow levels, the rocks are unreset and the slope of the AER reflects the actual $\dot{E}$. In rocks slightly deeper and partially reset, the AER is much shallower and would underestimate the $\dot{E}$ significantly or suggest a fossil partial-retention zone. Slightly deeper, the rocks are completely reset by magmatism and follow the same pattern as the cooling ages in the plutonic rocks. AERs closer to the pluton have the most extreme variability in slope and a greater proportion of the their vertical profile is dominated by ages fully or partially reset by magmatism.

\subsection{Tabular plutons}

Geophysical and field-based studies of upper crustal plutons suggest that many are tabular (Annen et al., 2015; Cruden \& McCaffrey, 2001). The tabular plutons in our models have two different sizes but equal height to length ratios, and the amount of time they are held at 750 ${ }^{\circ} \mathrm{C}$ is scaled by volume assuming a time-averaged emplacement rate of $10^{-2} \mathrm{~km}^{3} / \mathrm{yr}$ (de SaintBlanquat et al., 2011) rounded to the nearest kyr. The small pluton is $3 \mathrm{~km}$ in diameter and $1 \mathrm{~km}$ thick (Figure 1c), with a volume of $9 \mathrm{~km}^{3}$ and a heating time of $1 \mathrm{kyr}$. The large pluton is $15 \mathrm{~km}$

in diameter and $5 \mathrm{~km}$ thick (Figure 1d), with a volume of $125,000 \mathrm{~km}^{3}$ and a heating time of 113 kyr. We place them at very shallow crustal levels (pluton roof at $2 \mathrm{~km}$ depth) or slightly deeper (pluton roof at $5 \mathrm{~km}$ depth) and exhume them at 0.1 and $1 \mathrm{~km} / \mathrm{Myr}$ rates. 
Unlike the simplest pluton modeled in Section 5.1, the small tabular plutons modeled here do not occupy a significant fraction of the crustal column, so their emplacement depth relative to the chronometer $Z_{C}$ is the principal variable controlling the pattern and magnitude of magmatic cooling documented by that thermochronometer (Figure 7). When emplaced shallowly (Figure 7a,b), the small tabular pluton overlaps with the apatite $\mathrm{He} Z_{C}$, so the resetting aureole widens with proximity to $Z_{C}$ and is wider in the more rapidly exhuming scenario. In contrast, the same pluton emplaced $3 \mathrm{~km}$ deeper (Figure 7c,d) has no measurable effect on the cooling ages and $\xi=1$ through the entire crustal section with the exception of a narrow band of ages $\xi \approx 0.9$ near the $Z_{C}$ in the rapidly exhuming model (Figure $7 \mathrm{c}$ ).

The small shallow plutons are emplaced several kilometers above the zircon $\mathrm{He} Z_{C}$ (Figure 7e,f), therefore the resetting aureole is very narrow and is widest at the middle of the pluton. The deeper tabular plutons sit just above the zircon $\mathrm{He} Z_{C}$, so the resetting aureole is wider, and widens moderately with depth, but there is only modest contrast $(\xi>0.75)$ between the cooling ages inside and outside the resetting aureole (Figure $7 \mathrm{~g}, \mathrm{~h}$ ).

The large shallow pluton (Figure 8) intersects the apatite $\mathrm{He} Z_{C}$ like its smaller counterpart and generates a proportionally wider resetting aureole (Figure 8a, b). The large tabular pluton emplaced well below the apatite $\mathrm{He} Z_{C}$ generates significant resetting in the country rocks more than $3 \mathrm{~km}$ above it (Figure 8c,d). This effect is much greater in the model with $\dot{\mathrm{E}}=1 \mathrm{~km} / \mathrm{Myr}$ (Figure $8 \mathrm{c}$ ). The large tabular plutons emplaced at both depths intersect the zircon $\mathrm{He} Z_{C}$ (Figure 8e-h). As in the apatite He system, the zircon He ages kilometers above the pluton roof are reset by this large pluton (Figure $8 \mathrm{~g}, \mathrm{~h}$ ).

The timescale of conductive cooling is mostly controlled by pluton thickness (Equation 4, Appendix 1) and is therefore longer for the larger pluton. This, along with the longer heating time, is the principal reason the thermal footprint of these two plutons is different. Additionally, when $\dot{E}$ is faster, a larger part of the crustal column cools during the thermal relaxation of the pluton and captures part of that magmatic cooling. This follows from the scaling relationships described in Section 3.

In contrast, the extensive resetting in the country rocks above a large pluton, in some cases kilometers above the pluton roof and in both the apatite and zircon He systems (Figure 8), is a new insight from the thermo-kinematic modeling. It suggests that plutons emplaced deep in the crust could cause a significant thermal perturbation in the rocks above them. Next, we examine models of mid-crustal plutons to further characterize this phenomenon and its potential implications.

\section{Mid-crustal plutons reset upper-crustal country rocks}

\subsection{D numerical models}

To explore how low-temperature thermochronometric cooling ages document thermal perturbations from plutons emplaced far below thermochronometer closure depths, we examine 
cooling age patterns from the upper $10 \mathrm{~km}$ of the crust from Pecube models with mid-crustal plutons (Figure 1e). These plutons are tabular, $16 \mathrm{~km}^{2}$ by $6 \mathrm{~km}$ thick and emplaced at two different mid-crustal depths: 12 and $15 \mathrm{~km}$. These depths correspond to the brittle-ductile transition in the crust, where we assume magmatic ascent is interrupted (Burov et al., 2003). We hold them at $750{ }^{\circ} \mathrm{C}$ for $1 \mathrm{Myr}$ or $10 \mathrm{Myr}$, to simulate a large plutonic complex constructed over 1 Myr or a mid-crustal magma body acting as a recharging magma reservoir, respectively. The plutons are exhumed towards the surface at $0.1 \mathrm{~km} / \mathrm{Myr}$, so $100 \mathrm{~m}$ and $1 \mathrm{~km}$ of rock exhumation, respectively, occurs while they are held at $750^{\circ} \mathrm{C}$.

In all cases, the zircon and apatite He chronometers in rocks far above the mid-crustal plutons and close to $Z_{C}$ depths at the time of magmatism are significantly reset (Figure 9 ). The size of the upper-crustal resetting aureole scales with the proximity of the pluton and how long it was hot. But in most cases, this mid-crustal heating results in km-scale thick sections of crust with cooling ages approximately equal to the timing of magmatic activity $\left(\tau \sim \tau_{X}\right)$. Additionally, AERs are characterized by perturbations similar to those in country rocks immediately next to shallower upper-crustal plutons (Figure 6). These cooling age patterns could be interpreted as a change in exhumation rate, a period of rapid erosion, or a fossil partial-retention zone. Instead, they are simply the result of a transient increase in the geothermal gradient due to a thermal perturbation at depth.

\subsection{D analytical approximation}

To generalize the consequences of mid-crustal plutonism for low-temperature thermochronometers, we return to Laplace's solution to the one-dimensional unsteady heat conduction problem (Equation 5) but apply it now along the vertical coordinate, $z$. We use this solution to determine the extent of the thermal perturbation in the upper crust caused by a midcrustal pluton by assuming the pluton is much wider than it is thick (Appendix 2). The maximum temperature reached at a depth $z$ following the rapid cooling of a pluton with half-thickness $b_{Z}$ buried at a depth $z_{0}$ is given by:

$$
T_{\max }(z)=\frac{\Delta T_{0} b_{Z}}{z_{0}-z} \sqrt{\frac{1}{2 \pi e}}+T_{0} \frac{z}{z_{0}}
$$

$T_{0}$ is the temperature at depth $Z_{0}$ before the pluton emplacement and $T_{0}+\Delta T_{0}$ is the initial temperature of the pluton. We compute the depth, $z_{1}$, where the temperature will exceed a given closure temperature, $T_{c}$, at any time after the instantaneous cooling of the pluton:

$$
z_{1}=z_{0} \frac{T_{0}+T_{C}-\sqrt{\left(T_{0}+T_{C}\right)^{2}-4\left(T_{0} T_{c}-T_{0} \Delta T_{0} b_{Z} / z_{0} \sqrt{2 \pi e}\right)}}{2 T_{0}}
$$

We also compute the maximum temperature that would be reached at any depth if the pluton was held at a constant temperature for a very long (infinite) time: 


$$
T_{\max }^{\infty}=\left(T_{0}+\Delta T_{0}\right) \frac{z}{z_{0}}
$$

and from it, we can determine the depth, $z_{2}$, where the temperature will exceed the same closure temperature, $T_{c}$ :

$$
z_{2}=\frac{z_{0} T_{c}}{T_{0}+\Delta T_{0}}
$$

In Figure 10, we show how these two depths $z_{1}$ and $z_{2}$ vary as a function of $T_{C}$ and compare them to the unperturbed closure depth $Z_{C}$.

This simple analytical prediction agrees with the numerical model predictions in $3 \mathrm{D}$ (Figure 9). It provides a general guide for the potential extent of low-temperature thermochronometer resetting in the upper crust above large long-lived or short-lived magmatic bodies (of specific size) emplaced at depths much greater than $Z_{C}$.

\section{Implications for low-temperature cooling age interpretations}

Heating from intrusive magmatism most extensively resets low-temperature thermochronometers in country rocks that are colder than, but close to, the chronometer closure temperature (i.e., in the partial-retention or -annealing zone, PRZ, PAZ) at the time of magmatic activity. Around plutons emplaced at or above thermochronometer $Z_{C}$ depths, the resetting zones are localized aureoles around the pluton (Figures 6,7,8). Our models predict that mid-crustal magmatism can also reset thermochronometers at PRZ depths-thermochronometers in rocks that are kilometers above the pluton itself (Figures 8d, 9). It is useful to describe these resetting extents as local and regional effects, respectively.

Regional resetting may be especially relevant for felsic magmatic systems, which require Myr-scale crustal residence times to produce evolved magma compositions if they were originally fed by mafic magmas. Additionally, because isolated, shallowly emplaced plutons are merely the top of a more voluminous magmatic system that plumbs the middle and lower crust, in some regions it may be critical to consider both the local heating around observed individual upper-crustal plutons and the regional thermal effects of the related magmatic system at depth. Such systems would have an additive heating effect that is thought to produce low-pressure metamorphic belts (Barton \& Hanson, 1989; Hanson \& Barton, 1989).

It appears that the common practice of using the crystallization ages of magmatic rocks mapped at the surface as a spatial-temporal guide for interpreting cooling ages can be insufficient in regions with a history of mid-crustal magmatism. Model results predict that plutons emplaced in the middle crust and not yet exhumed are capable of resetting low-temperature thermochronometers in the upper crust without any surface expression. In other words, the lowtemperature thermochronologic record of a mid-crustal pluton's emplacement forms at shallower depths, and will be exhumed before the pluton itself. Such regional resetting may be particularly important in magmatic arcs, where plutonism occurs continuously at geologic timescales, and 
therefore surface mapping can document only part of the magmatic history relevant to thermochronologic interpretations.

The resetting signal produced by mid-crustal plutons is only present in rocks that were at PRZ depths at the time of plutonic activity. Therefore, this reset zone must be subsequently exhumed to the surface (or sampled in a borehole) to be observed. For example, if it is independently known that rocks at the surface today were at apatite He partial-retention depths (i.e., $\sim 2 \mathrm{~km}$; Figure 10a) in the past at a time of known magmatic activity, the apatite He cooling ages of these rocks should be interpreted with caution. In contrast, zircon He ages from the same rocks were likely too shallow and therefore too cold to be reset by the same magmatic event and the pre-magmatic cooling history would be preserved in the zircon He system. For the regional magmatic cooling signal to be observed in zircon He ages at the surface today, post-magmatic exhumation of $\sim 4-5 \mathrm{~km}$ (Fig. 10a) would be required to exhume rocks from zircon He PRZ depths.

This study simulates bedrock cooling ages but has implications for detrital thermochronology. Sedimentary sections with material shed during the unroofing of magmatic terranes can have detrital cooling ages that reflect both magmatic and exhumational cooling of the source region. When shallowly emplaced plutons are exhumed in a source terrane, rocks from both the pluton and resetting aureole erode may be deposited at the same time. Therefore, as in the bedrock scenarios modeled here, the high-temperature geochronometer (crystallization) ages in detrital minerals can provide an important reference age to compare to the lowtemperature cooling ages (e.g., Malusa et al., 2011). In contrast, the resetting aureoles formed above mid-crustal plutons will exhume before the plutons and produce a detrital thermochronologic signal that could, as in interpretations of bedrock AERs, appear to document a period of rapid exhumation in the source terrane.

This is one of many common complexities in nature that we do not directly explore here because we limited our models to steadily exhuming bedrock landscapes with no topography. Our results do, however, provide a general framework for interpreting cooling ages in magmatic terranes by clarifying the role of two parts of a terrane's history: the pre- and post-magmatic histories.

The pre-magmatic history sets both the cooling-age field and thermal field into which a pluton intrudes. The cooling-age field controls the age contrast between the reset, partially reset, and unreset thermochronometers (i.e., $\xi$ ). It therefore governs how magmatic cooling ages will be in manifest in the geologic record. The pre-magmatic thermal field controls the spatial extent and pattern of thermochronometer resetting at depth during magmatism. A terrane's postmagmatic exhumation history controls whether rocks that document magmatic cooling are in an accessible part of the geologic record, i.e., at the surface today or incorporated into the detrital thermochronologic record. 
The shape of the surface boundary condition (i.e., the pre- and syn-magmatic surface topography) is an important variable - especially for the lowest-T chronometers - that we do not explore here. If, for example, plutonism occurs in a region with km-scale topographic relief, then plutons will intrude into a thermal field with corresponding relief in the upper crustal isotherms. Therefore, the resetting aureoles will be shaped by the topography of the surface boundary condition. Particularly interesting complications may arise if the surface boundary conditions change as a result of ongoing plutonism. For example, shallowly emplaced tabular plutons (e.g., laccoliths) commonly uplift the country rocks, and potentially surface, above them. This creates surface topography as well as the potential for magmatism-driven exhumation (Gilbert, 1877). Given the number of possible variables (the thermochronometers of interest; the pluton size, depth, and emplacement time; the initial topography and its evolution over time; the timescale and spatial scale of the erosional response to uplift, etc.), it is not possible to generalize about the effects of this on the low-temperature thermochronologic record. Our modified version of Pecube is, however, capable of exploring some specific scenarios or situations applicable to a given case study.

\section{Conclusions}

The analytical and numerical modeling results presented here offer a new perspective on how to best interpret low-temperature thermochronologic cooling ages inside and around plutonic rocks. Laplace's analytical solution to the unsteady heat conduction problem in a 1D infinite region predicts the importance of the ambient temperature at depth, $T_{Z}$, in controlling the spatial extent of thermochronometer resetting. The resetting aureole for a thermochronometric system is widest at depths close to the closure temperature $T_{C}$ (Figure 2a), and therefore the extent of resetting around a pluton is not just a function of its size and temperature. The thermokinematic model Pecube, which numerically solves the 3D heat transport equation and calculates thermochronometer cooling ages, supports the predictions from Laplace's solution and predicts how the thermal perturbations produced by simple plutons of various sizes and emplacement depths affect thermochronometers, given different constant exhumation rates.

The scaling relationships that define the Péclet number, $P e$, describe how the cooling history of rocks inside and around a pluton is governed by the competition between exhumationdriven (or advective) cooling and conductive cooling of the pluton and through the Earth's surface (Figure 5). In models with rapid exhumation, advective heat transport dominates. As a result, a larger section of the crust is affected by the thermal perturbation introduced by the pluton in horizontal and vertical dimensions, but the absolute difference between reset and unreset cooling ages (Myr) is small because rock cooling is very rapid and all cooling ages are very young (Figure 6).

In all cases where a pluton is emplaced at depths close to or above a thermochronometer closure temperature, the resetting aureole(s) in the surrounding country rocks create substantial changes in the slope of vertical age-elevation relationships (AERs, Figure 6). Such changes in 
AER slope are commonly used to infer past changes in exhumation rate or periods of rapid erosion, but here they simply reflect the magmatic perturbation of the geothermal gradient in a steadily exhuming landscape. Interpreting these AER patterns as changes in exhumation rate would result in over or underestimating it orders of magnitude.

Our models predict similar AER patterns can form in rocks in the upper crust directly above large mid-crustal plutons emplaced at 10-15 km depth (Figure 9). The extent of the thermal perturbation caused by these deeply emplaced plutons scales with their thickness, depth of emplacement, and longevity (Figure 10, Appendix 2). The effects are focused in rocks at ambient temperatures close to $T_{C}$ at the time of magmatic activity, so in order to see this effect in the geologic record, the rocks at close to $Z_{C}$ depths at the time of regional magmatism must be subsequently exhumed. Importantly, this suggests that the plutons mapped at the surface may not be a sufficient record of the potential thermal perturbations bedrock samples at the surface today experienced.

The flat, constantly exhuming magmatic terranes modeled here are simple but instructive models of regions where low-temperature thermochronology is used to investigate landscape evolution. These models illustrate that (1) a region's pre- and syn-magmatic exhumation history sets the thermal and cooling-age fields into which a pluton intrudes, and (2) a region's postmagmatic exhumation history controls whether rocks that document magmatic cooling are observed in the bedrock or detrital thermochronologic record. Many natural settings have topographic relief and variable exhumation that would add additional complexity. These complexities make it even more critical to recognize the first-order control the pre-magmatic and post-magmatic histories have in shaping the pattern and preservation of magmatic cooling signals in the thermochronologic record.

\section{Appendix 1 Pluton cooling timescales}

The cooling of a pluton of thickness $b_{Z}$ and radius $b_{X Y}$, emplaced at a depth $z_{0}$ in a lithosphere of thickness $L$ (Figure A1), is characterized by a range of conductive timescales, each corresponding to a particular length scale. Assuming that the pluton thickness is smaller than its depth $\left(b_{Z}<z_{0}\right)$ and that its radius is larger than its thickness $\left(b_{Z}<b_{X Y}\right)$, they are: the timescale for cooling of the entire lithosphere (assuming that the temperature at the base of the lithosphere is constant),

$$
\bar{\tau} \approx \frac{L^{2}}{\kappa \pi^{2}}
$$

the timescale for cooling at the center of the pluton,

$$
\tau_{c} \approx \frac{b_{Z}^{2}}{\kappa \pi^{2}}
$$

the timescale for cooling of the crust adjacent to the pluton but at the same depth, 


$$
\tau_{R} \approx \frac{b_{X Y}^{2}}{\kappa \pi^{2}}
$$

And the timescale for cooling near the surface,

$$
\tau_{0} \approx \frac{z_{0}^{2}}{\kappa \pi^{2}}
$$

We note that each timescale is defined by the length scale defined in the direction of heat conductive transport for the location under consideration.

We tested the validity of these relationships by numerically solving the heat conduction equation in cylindrical coordinates $(r, \phi, z)$, positioning the pluton along the $r=0$ axis and assuming azimuthal symmetry. We included a uniform radiogenic heat production. We tracked the mean temperature, the temperature at the center of the pluton, the temperature near the surface and the temperature next to the pluton at the same depth. We used a second-order accurate, centered difference scheme to estimate the Laplacian and an explicit scheme for the time evolution. In Figure A2, we show, for example, the time evolution of the temperature at the center of the pluton for various values of $b_{X Y}$ (Figure A2a), $b_{Z}$ (Figure A2b), $L$ (Figure A2c) and $z_{0}$ (Figure A2d). We see that the response time for the cooling at the center of the pluton is principally controlled by $b_{Z}$, the pluton thickness, as long as it is substantially smaller than its radius and its depth of emplacement.

\section{Appendix 2 Thermal perturbation of a mid-crustal pluton 'hidden' at depth}

We can use Laplace's solution to the one-dimensional unsteady heat conduction equation (Equation 5) to determine the extent of the thermal perturbation caused by a deep crustal pluton, if we assume that the pluton is much wider than thick (i.e. it is a tabular pluton, Figure A3).

Note that Laplace's solution does not fully apply to the problem at hand, as it assumes that the medium in which the pluton intrudes is infinite. The exact solution that takes into account that the surface is characterized by a finite (nil) temperature is given by the following infinite series:

$$
\Delta T(z, t)=\sum_{n=1}^{\infty} \frac{4 \Delta T_{0}}{n \pi} \sin \frac{n \pi z_{0}}{L} \sin \frac{n \pi b}{L} \sin \frac{n \pi z}{L} e^{-\frac{n^{2} \pi^{2} t \kappa}{L^{2}}}
$$

In Figure A4, we compare Laplace's solution to the maximum temperature predicted by the exact solution and note that they are identical in the vicinity of the pluton and only diverge by less than $10 \%$ near the surface. Because of its simplicity, we use Laplace's solution.

\section{Acknowledgements}

The code for Pecube can be found in Braun et al. (2011). This paper is theoretical and no data are used. KEM acknowledges support from a NSF GRFP award, ARCS Phoenix Chapter Prentice Scholarship, a GSA student research grant, and a P.E.O. Scholar Award. JB acknowledges support from GFZ German Research Center for Geosciences. Thank you to 
Thibault Simon-Labric for discussions pluton heating effects on thermochronology; to Mihai Ducea, Jay Quade, and George Davis for comments on early versions of this work; and to graduate students and faculty at ISTerre for welcoming KEM during visits to Grenoble, France. Additional thanks to Kiriaki Xiluri-Lauria for technical support. This manuscript benefitted from thoughtful reviews by Julie Fosdick and one anonymous reviewer.

\section{References}

Annen, C. (2011). Implications of incremental emplacement of magma bodies for magma differentiation, thermal aureole dimensions and plutonism-volcanism relationships. Tectonophysics, 500(1-4), 3-10. https://doi.org/10.1016/j.tecto.2009.04.010

Annen, C., Blundy, J. D., Leuthold, J., \& Sparks, R. S. J. (2015). Construction and evolution of igneous bodies: Towards an integrated perspective of crustal magmatism. Lithos, 230(C), 206-221. https://doi.org/10.1016/j.lithos.2015.05.008

Barton, M. D., \& Hanson, R. B. (1989). Magmatism and the development of low-pressure metamorphic belts: Implications from the western United States and thermal modeling. Geological Soceity of America Bulletin, 101(8), 1051-1065. https://doi.org/10.1130/0016-7606(1989)101<1051:MATDOL>2.3.CO;2

Braun, J. (2003). Pecube: a new finite-element code to solve the 3D heat transport equation including the effects of a time-varying, finite amplitude surface topography. Computers \& Geosciences, 29(6), 787-794. https://doi.org/10.1016/S0098-3004(03)00052-9

Braun, J., van der Beek, P., Valla, P., Robert, X., Herman, F., Glotzbach, C., et al. (2011). Quantifying rates of landscape evolution and tectonic processes by thermochronology and numerical modeling of crustal heat transport using PECUBE. Tectonophysics, 524525, 1-28. https://doi.org/10.1016/j.tecto.2011.12.035

Brown, R., Gallagher, K., \& Duane, M. (1994). A quantitative assessment of the effects of magmatism on the thermal history of the Karoo sedimentary sequence. Journal of African Earth Sciences, 18(3), 227-243. https://doi.org/10.1016/0899-5362(94)90007-8

Burov, E., Jaupart, C., \& Guillou-Frottier, L. (2003). Ascent and emplacement of buoyant magma bodies in brittle-ductile upper crust. Journal of Geophysical Research-Solid Earth, 108(B4), 2177. https://doi.org/10.1029/2002JB001904

Calk, L. C., \& Naeser, C. W. (1973). The Thermal Effect of a Basalt Intrusion on Fission Tracks in Quartz Monzonite. The Journal of Geology, 81(2), 189-198. https://doi.org/10.1086/627834

Cruden, A. R., \& McCaffrey, K. (2001). Growth of plutons by floor subsidence: Implications for rates of emplacement, intrusion spacing and melt-extraction mechanisms. Physics and Chemistry of the Earth Part a-Solid Earth and Geodesy, 26(4-5), 303-315. https://doi.org/10.1016/S1464-1895(01)00060-6 
de Saint-Blanquat, M., Horsman, E., Habert, G., Morgan, S., Vanderhaeghe, O., Law, R., \& Tikoff, B. (2011). Multiscale magmatic cyclicity, duration of pluton construction, and the paradoxical relationship between tectonism and plutonism in continental arcs. Tectonophysics, 500(1-4), 20-33. https://doi.org/10.1016/j.tecto.2009.12.009

Dodson, M. (1973). Closure temperature in cooling geochronological and petrological systems, Contributions to Mineralogy and Petrology, 40(3), 259-274. https://doi.org/10.1007/BF00373790

Dumitru, T., Gans, P., Foster, D., \& Miller, E. (1991). Refrigeration of the western Cordilleran lithosphere during Laramide shallow-angle subduction, 19(11), 1145-1148. https://doi.org/10.1130/0091-7613(1991)019<1145:ROTWCL>2.3.CO;2

Ehlers, T. A. (2005a). Computational Tools for Low-Temperature Thermochronometer Interpretation. Reviews in Mineralogy and Geochemistry, 58(1), 589-622. https://doi.org/10.2138/rmg.2005.58.22

Ehlers, T. A. (2005b). Crustal Thermal Processes and the Interpretation of Thermochronometer Data. Reviews in Mineralogy and Geochemistry, 58(1), 315-350. https://doi.org/10.2138/rmg.2005.58.12

Fu, F. Q., McInnes, B. I. A., Evans, N. J., \& Davies, P. J. (2010). Numerical modeling of magmatic-hydrothermal systems constrained by $\mathrm{U}-\mathrm{Th}-\mathrm{Pb}-\mathrm{He}$ time-temperature histories. Journal of Geochemical Exploration, 106(1-3), 90-109. https://doi.org/10.1016/j.gexplo.2009.09.001

Gilbert, G.K. (1877). Report on the Geology of the Henry Mountains. Washington, D.C.: U.S. Government Printing Office.

Glazner, A., Bartley, J., Coleman, D., Gray, W., \& Taylor, R. (2004). Are plutons assembled over millions of years by amalgamation from small magma chambers? GSA Today, 14(4/5), 4-12. https://doi.org/10.1130/1052-5173(2004)0142.0.CO;2

Guenthner, W. R., Barbeau, D. L., Jr., Reiners, P. W., \& Thomson, S. N. (2010). Slab window migration and terrane accretion preserved by low-temperature thermochronology of a magmatic arc, northern Antarctic Peninsula. Geochemistry Geophysics Geosystems, 11(3), Q03001. https://doi.org/10.1029/2009GC002765

Guillaume, B., Gautheron, C., Simon-Labric, T., Martinod, J., Roddaz, M., \& Douville, E. (2013). Dynamic topography control on Patagonian relief evolution as inferred from low temperature thermochronology. Earth and Planetary Science Letters, 364, 157-167. https://doi.org/10.1016/j.eps1.2012.12.036

Hanson, R. B., \& Barton, M. D. (1989). Thermal development of low-pressure metamorphic belts: Results from two-dimensional numerical models. Journal of Geophysical 
Research, 94, 10363-10377.

https://doi.org/10.1029/JB094iB08p10363/asset/jgrb7145.pdf

Harrison, T. M., \& Clarke, G. K. C. (1979a). A model of the thermal effects of igneous intrusion and uplift as applied to Quottoon pluton, British Columbia. Canadian Journal of Earth Sciences, 16(3), 411-420. https://doi.org/10.1139/e79-039

Harrison, T., \& Clarke, G. K. (1979b). Model of the thermal effects of igneous intrusion and uplift as applied to Quottoon pluton, British Columbia. Canadian Journal of Earth Sciences, 16(3), 411-420. https://doi.org/10.1139/e79-039

House, M. A., Kelley, S. A., \& Roy, M. (2003). Refining the footwall cooling history of a rift flank uplift, Rio Grande rift, New Mexico. Tectonics, 22(5), 1060. https://doi.org/10.1029/2002TC001418

House, M. A., Wernicke, B. P., \& Farley, K. A. (1998). Dating topography of the Sierra Nevada, California, using apatite (U-Th)/He ages. Nature, 396(6706), 66-69. https://doi.org/10.1038/23926

Huber, C., Bachmann, O., \& Manga, M. (2009). Homogenization processes in silicic magma chambers by stirring and mushification (latent heat buffering). Earth and Planetary Science Letters, 283(1-4), 38-47. https://doi.org/10.1016/j.eps1.2009.03.029

Jaeger, J. C. (1964). Thermal effects of intrusions. Reviews of Geophysics, 2(3), 443-466. https://doi.org/10.1029/RG002i003p00443

Ketcham, R. A. (2005). Forward and inverse modeling of low-temperature thermochronometry data. Reviews in Mineralogy and Geochemistry, 58, 275-314. https://doi.org/10.2138/rmg.2005.58.11

Lovera, O., Grove, M., Kimbrough, D., \& Abbott, P. (1999). A method for evaluating basement exhumation histories from closure age distributions of detrital minerals. Journal of Geophysical Research, 104(B12), 29419-29438. https://doi.org/10.1029/1999JB900082

Malusà, M. G., Villa, I. M., Vezzoli, G., \& Garzanti, E. (2011). Detrital geochronology of unroofing magmatic complexes and the slow erosion of Oligocene volcanoes in the Alps. Earth and Planetary Science Letters, 301(1-2), 324-336. https://doi.org/10.1016/j.epsl.2010.11.019

McInnes, B., Evans, N., Fu, F., \& Garwin, S. (2005). Application of thermochronology to hydrothermal ore deposits. Reviews in Mineralogy and Geochemistry, 58(1), 467. https://doi.org/10.2138/rmg.2005.58.18

Murray, K. E., Reiners, P. W., \& Thomson, S. N. (2016). Rapid Pliocene-Pleistocene erosion of the central Colorado Plateau documented by apatite thermochronology from the Henry Mountains. Geology, 44(6), 483-486. https://doi.org/10.1130/G37733.1 
Nabelek, P. I., Hofmeister, A. M., \& Whittington, A. G. (2012). The influence of temperaturedependent thermal diffusivity on the conductive cooling rates of plutons and temperaturetime paths in contact aureoles. Earth and Planetary Science Letters, 317-318(C), 157164. https://doi.org/10.1016/j.eps1.2011.11.009

Norton, D., \& Knight, J. (1977). Transport Phenomena in Hydrothermal Systems: Cooling Plutons. American Journal of Science, 277(8), 937-981. https://doi.org/10.1093/petrology/20.3.421

Norton, D., \& Taylor, H. P. (1979). Quantitative Simulation of the Hydrothermal Systems of Crystallizing Magmas on the Basis of Transport Theory and Oxygen Isotope Data: An analysis of the Skaergaard Intrusion. Journal of Petrology, 20(3), 421-486. https://doi.org/10.1093/petrology/20.3.421

Parmentier, E. M., \& Schedl, A. (1981). Thermal Aureoles of Igneous Intrusions - Some Possible Indications of Hydrothermal Convective Cooling. The Journal of Geology, 89(1), 1-22. https://doi.org/10.2307/30061180

Reiners, P.W., and Brandon, M.T., (2006). Using thermochronology to understand orogenic erosion. Annual Review of Earth and Planetary Sciences, 34(1), 419-466. doi: 10.1146/earth.2006.34.issue-1.

Reiners, P. W., Ehlers, T. A., Mitchell, S. G., \& Montgomery, D. R. (2003). Coupled spatial variations in precipitation and long-term erosion rates across the Washington Cascades. Nature, 426(6967), 645-647. https://doi.org/doi:10.1038/nature02111

Roy, M., Kelley, S., Pazzaglia, F., Cather, S., \& House, M. (2004). Middle Tertiary buoyancy modification and its relationship to rock exhumation, cooling, and subsequent extension at the eastern margin of the Colorado Plateau. Geology, 32(10), 925-928. https://doi.org/10.1130/G20561.1

Taylor, J. P., \& Fitzgerald, P. G. (2011). Low-temperature thermal history and landscape development of the eastern Adirondack Mountains, New York: Constraints from apatite fission-track thermochronology and apatite (U-Th)/He dating. Geological Society of America Bulletin, 123(3-4), 412-426. https://doi.org/10.1130/B30138.1

Thomson, S. N., Brandon, M. T., Tomkin, J. H., Reiners, P. W., Vásquez, C., \& Wilson, N. J. (2010). Glaciation as a destructive and constructive control on mountain building. Nature, 467(7313), 313-317. https://doi.org/10.1038/nature09365

Turcotte, D. L., \& Schubert, G. (2002). Geodynamics (Second Edition). New York, New York: Cambridge University Press.

This article is protected by copyright. All rights reserved. 
Table 1. Abbreviations and units in this study.

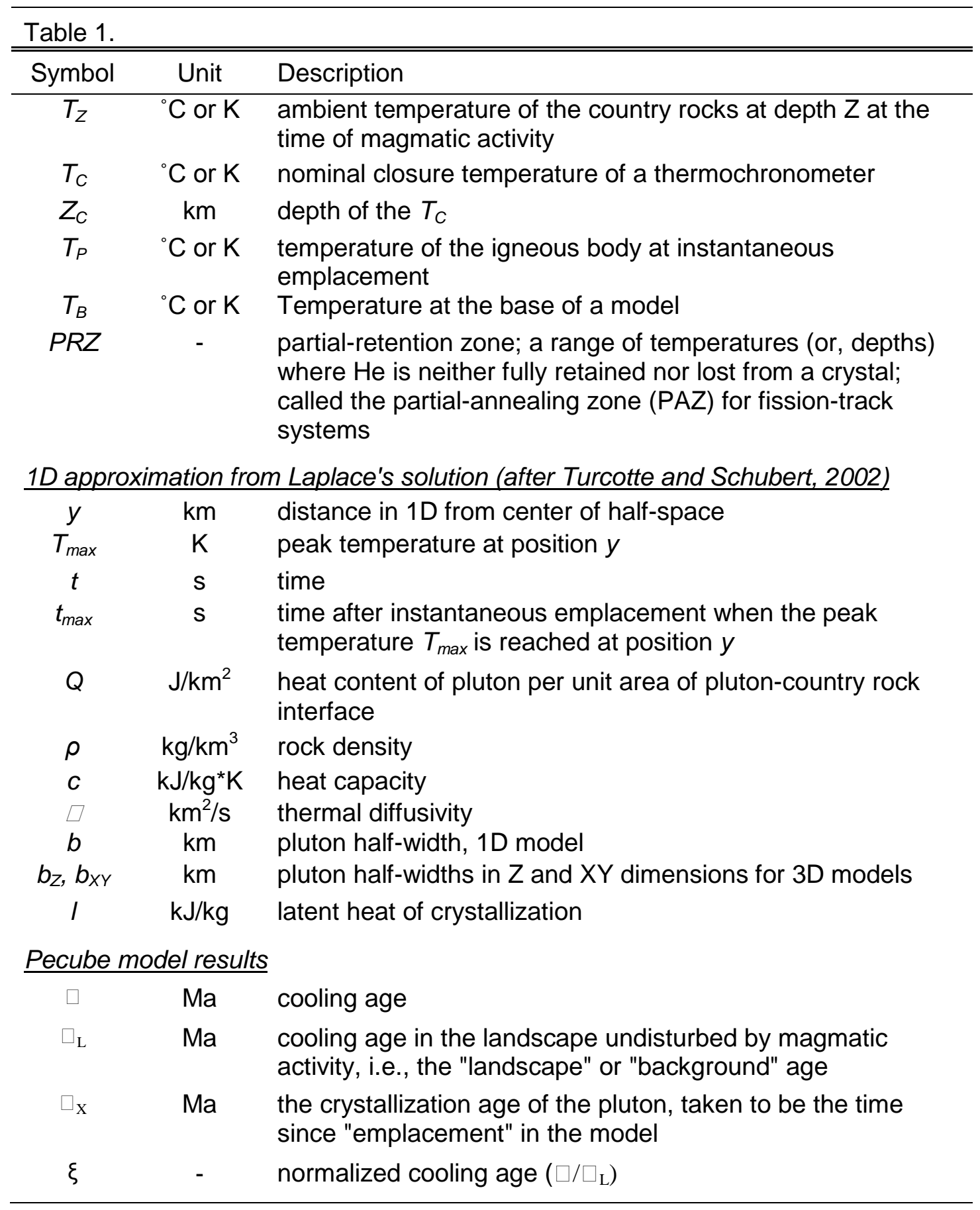

This article is protected by copyright. All rights reserved. 
Table 2. Thermo-kinematic parameters used in Pecube models.

\begin{tabular}{lcc}
\hline Table 2. & & \\
\hline \hline Parameter & Value & Unit \\
\hline Crustal thickness & varies & $\mathrm{km}$ \\
Thermal diffusivity & 25 & $\mathrm{~km}^{2} / \mathrm{Myr}$ \\
Basal crustal temperature $\left(\mathrm{T}_{\mathrm{B}}\right)^{\mathrm{a}}$ & varies & ${ }^{\circ} \mathrm{C}$ \\
Sea-level temperature & 0 & ${ }^{\circ} \mathrm{C}$ \\
Atmospheric lapse rate & 0 & ${ }^{\circ} \mathrm{C} / \mathrm{km}$ \\
Crustal heat production & 0 & ${ }^{\circ} \mathrm{C} / \mathrm{Myr}$ \\
lgneous body temperature $\left(\mathrm{T}_{\mathrm{P}}\right)$ & 750 & ${ }^{\circ} \mathrm{C}$ \\
\hline Note: Elastic parameters not reported because \\
isostatic response to relief change is not modeled. \\
a Model basal temperature selected assuming a 25 \\
${ }^{\circ} \mathrm{C} / \mathrm{km}$ linear geothermal gradient and a given \\
crustal thickness
\end{tabular}

Figure 1. Summary of this study's modeling approaches. (a) Laplace's solution to onedimensional unsteady heat conduction problem in an infinite region provides simple predictions of the temperature and cooling age patterns around plutons. (b) The numerical model Pecube solves for the thermal field for different exhumation rates and calculates cooling ages in and around the pluton. The simplest model in Pecube is similar to Laplace's solution in 3D, with a tall narrow pluton emplaced in the upper $10 \mathrm{~km}$ of the crust. (c) Small tabular plutons and (d) large tabular plutons have more geologically realistic shapes in 3D. (e) Models with tabular plutons emplaced at 12-15 km depths explore the effects of mid-crustal magmatism on upper crustal thermochronometers.

Figure 2. We use Laplace's solution to find the shape of the resetting aureole for a single thermochronometric system and the resulting schematic horizontal cooling age patterns. (a) Cross section through a thermochronometer resetting aureole was constructed by solving Equation 10 for a range of ambient temperatures. The width of the resetting aureole is a function of temperature at depth $\mathrm{Z}, T_{Z}$. The closer $T_{Z}$ is to the closure temperature $T_{C}$, the wider the resetting aureole. Horizontal lines labeled 1-4 indicate the depth of cooling age transects in panel $\mathrm{b}$ at the time of magmatism. (b) Schematic horizontal cooling age transects given the dimensions of the resetting aureole in a. Close to the pluton, the cooling ages are completely reset and the age of the pluton emplacement $\left(\tau_{X}\right)$. Far from the pluton, the cooling ages are unaffected by magmatic heating and set by the exhumation rate $\left(\tau_{L}\right)$. Note that as time passes and deeper rocks are exhumed, the pluton's crystallization age $\tau_{X}$ gets older. In rocks at shallow depths at the time 
of magmatism (i.e., at cold $T_{Z}$; transect 1 ), the resetting aureole is narrow and the age difference between reset and unreset ages is large. Transects exhumed later through the same surface from increasingly greater depths and hotter $T_{Z}$ have increasingly wider resetting aureoles but smaller cooling age differences across the transect.

Figure 3. Laplace's solution predicts the spatial relationship between thermochronometric systems with different closure temperatures and suggests vertical cooling age patterns at different distances from the pluton for a single system. (a) Analytical approximations of the resetting aureoles of the four commonly used low-temperature thermochronometers, created by solving Equation 10 with the following parameters: closure temperature $T_{C}$ for each system given a 10 ${ }^{\circ} \mathrm{C} / \mathrm{Myr}$ cooling rate (Reiners \& Brandon, 2006), a pluton with half-width $b=0.5 \mathrm{~km}$ and temperature $T_{P}=750{ }^{\circ} \mathrm{C}$, and ambient temperatures $T_{Z}$ from 10 to $250{ }^{\circ} \mathrm{C}$. Vertical lines indicate the position of vertical profiles in panels c-d. (b) Zircon He ages as a function of $T_{Z}$ for a constant $10{ }^{\circ} \mathrm{C} / \mathrm{Myr}$ cooling rate (i.e., a constant exhumation rate $\dot{E}$ ) as predicted by the thermal history modeling code HeFTy (Ketcham, 2005) using standard zircon He diffusion kinetics. At the surface the cooling age is $\tau_{L}$. Where $T_{Z}>T_{C}$ the cooling age is zero. (c) Zircon He age vs. $T_{Z}$ patterns (i.e., age-depth or age-elevation relationships) immediately after pluton cooling at three locations: the edge of the pluton (square), at $y / b=3$ (diamond), and $y / b=10$ (circle) distance from the pluton center. For the purposes of generally describing the cooling age patterns that would result from resetting around plutons using Laplace's approximation, we assume that when the peak $T>T_{C}$ a chronometer is completely reset. A heating event would perturb the age- $T_{Z}$ relationship in panel $b$, creating sharp changes in the slope of a vertical profile at the transitions into an out of a resetting aureole. (d) As constant (exhumation-driven) cooling at a rate of 10 ${ }^{\circ} \mathrm{C} / \mathrm{Myr}$ continues after pluton emplacement, the perturbed age- $T_{Z}$ relationship is progressively exhumed. At this rate it takes $\sim 20 \mathrm{Myr}$ exhume all the rocks that were colder than the zircon He $T_{C}\left(\sim 183{ }^{\circ} \mathrm{C}\right)$ at the time of pluton emplacement and entirely re-establish an age- $T_{Z}$ relationship in (b). Rocks from depths where $T_{Z} \gg T_{C}$ at the time of magmatism do not document magmatic cooling because they had a zero age at the time of pluton emplacement. Each thermochronologic system would have these patterns, which would be nested as a function of $T_{C}$.

Figure 4. Horizontal normalized cooling age $\left(\xi=\tau / \tau_{L}\right)$ transects from normalized $Z / Z_{C}$ depths (a) across the simplest pluton exhumed at $\dot{E}=0.01$ (b,c), 0.1 (d,e), and $1 \mathrm{~km} / \mathrm{Myr}(\mathbf{f}, \mathbf{g})$, from the center of the pluton to the edge of the Pecube model domain. The grey field indicates rocks in pluton domain held at $750{ }^{\circ} \mathrm{C}$. Where $\xi=1$, the cooling age documents only exhumation-driven cooling. In horizontal transects from slowly exhuming scenarios and from rocks that were cold relative to the chronometer $T_{C}$, the normalized cooling age $\xi$ in the pluton is approximately equal to the $Z / Z_{C}$ and the transition between reset to unreset ages is sharp. Transects from rocks close to $Z_{C}$ at the time of magmatism and from rapidly exhuming models deviate from this $\xi=Z / Z_{C}$ trend and have wider resetting aureoles. 
Figure 5. Temperature-depth profiles from a 1D numerical model that solves the vertical heat conduction-advection equation. Depth and temperature are normalized by the thickness of the layer being exhumed and the maximum (fixed) temperature at the base of the layer, respectively. Each panel $(\mathbf{a}, \mathbf{b}, \mathbf{c})$ corresponds to different values of the exhumation velocity that translates into different values of the Peclet number, $P e$. The thick blue line is the steady-state temperature profile set by $\dot{E}$. We assume that a pluton has been emplaced at $t=0$ in the center of the layer. It has a thickness of 0.2 and an initial temperature of 1.5 (i.e., 1.5 the temperature at the base of the layer), which creates the initial temperature profile (orange line). Black lines are the temperaturedepth profiles at 10 time steps separated by the time it takes to advect a point by 0.05 , such that at the end of the 10 time steps, a point that was located in the center of the layer at $t=0$ (shown by the red circles) reaches the surface. We see that the temperature anomaly caused by the pluton decays much more rapidly in the case of a small value of $P e(P e=0.1)$ compared to a large value of $P e(P e=10)$. This is simply because in the case of fast exhumation (large $P e$ ), the time necessary to advect the rock towards the surface is much shorter but the conductive cooling time is unchanged, and as a result the conductive relaxation of the temperature anomaly caused by the pluton is less efficient. This implies that the rock being exhumed at the center of the pluton remains hotter, i.e. above the initial, steady-state temperature profile (thick grey line), and potentially above the closure temperature of the thermochronometer under consideration, for a longer period of time, therefore resulting in a smaller value of $\xi\left(\tau / \tau_{L}\right)$ at a given $Z / Z_{C}$ depth.

Figure 6. Pecube model results from the simplest pluton scenarios (Figure 1b) stacked into vertical cross sections and synthetic age-elevation relationships (AERs). (a) Apatite He ages predicted from models with exhumation rates, $\dot{E}$, of $0.01,0.1$, and $1 \mathrm{~km} / \mathrm{Myr}$. Left panels present normalized cooling age $\left(\xi=\tau / \tau_{L}\right)$ contoured in vertical cross section. Where $\xi<1$, red-yellow colors indicate the contrast between the cooling age, $\tau$, and the unreset landscape age, $\tau_{L}$, in the resetting aureole. Dotted line indicates the depth of the $T_{C}$ set by $\dot{E}$. As predicted by the $1 \mathrm{D}$ solution, the resetting aureole is widest in rocks that were close to the $Z_{C}$ at the time of magmatism. Vertical colored lines indicate the location of profiles shown in middle and right panels. These vertical profiles report the age difference (in Myr) between the reset and unreset ages (middle panels) and the AER shape (right panels) inside the pluton and at different distances away. Note that the sampling resolution is every $500 \mathrm{~m}$ and starting at $1 \mathrm{~km}$ depth, so some details of the apatite He patterns are lost. (b) Zircon He ages predicted from the same models.

Figure 7. Model predictions for small tabular plutons (Figure 1c), shown as contoured $\xi\left(\tau / \tau_{L}\right)$ values in vertical cross section as in Figure 6.

Figure 8. Model predictions for large tabular plutons (Figure 1d), shown as contoured $\xi\left(\tau / \tau_{L}\right)$ values in vertical cross section as in Figure 6. 
Figure 9. Large tabular plutons emplaced in the middle crust (Figure 1e) heat the rocks above in the upper crust and reset the apatite and zircon He systems. The exhumation rate $\dot{E}$ is 0.1 $\mathrm{km} / \mathrm{Myr}$ and the apatite $\mathrm{He} \tau_{L}$ is $25 \mathrm{Ma}$ and the zircon He $\tau_{L}$ is $68 \mathrm{Ma}$. This resetting is shown in contoured $\xi\left(\tau / \tau_{L}\right)$ values as well as the difference (Myr) between the landscape age $\tau_{L}$ and age $\tau$ (in Myr) at three positions: in the middle of the model directly above the center of the pluton, above the edge of the pluton, and in the rocks $b_{X Y}$ distance from the pluton edge. Age differences of $<10 \%$ between $\tau_{L}$ and $\tau$ (i.e., $\xi>0.9$ ) are not mapped in the $\xi$ plot but are evident in the age difference vs. depth plot. Synthetic age-elevation relationships (AERs) at each of these positions were constructed assuming $10 \mathrm{~km}$ of exhumation (and 100 Myr elapsed) since pluton emplacement ended. (a) Tabular pluton emplaced at $15 \mathrm{~km}$ depth and hot for 1 Myr. Rocks in the crust above this pluton close to $Z_{C}$ at the time of magmatism are fully or partially reset by this thermal event. (b) Pluton at $12 \mathrm{~km}$ depth, hot for 1 Myr. (c) Pluton at $15 \mathrm{~km}$ depth, hot for 10 Myr. (d) Pluton at $12 \mathrm{~km}$ depth, hot for $10 \mathrm{Myr}$.

Figure 10. Laplace's analytical solution used to determine the crustal depths that would experience $T>T_{C}$ as the result of the presence of an instantaneously cooled (blue field) or longlived (infinite, red field) pluton located directly below in the middle crust. The black line is the depth vs. temperature in an unperturbed linear geothermal gradient of $30{ }^{\circ} \mathrm{C} / \mathrm{km}$. This line is also the depth of any temperature of interest, such as a $T_{C}$. Blue and red lines identify the shallower depths where the same temperature would be (e.g., where $T=T_{C}$ ) as a result of the instanteously cooled or long-lived pluton, respectively. The pluton temperature $\left(T_{0}+\Delta T_{0}\right)$ is $750{ }^{\circ} \mathrm{C}$. Broad ranges for the temperature sensitivities of the three lowest-temperature thermochronometric systems identified for reference. This approach provides a general guide for the extent of resetting above mid-crustal plutonic systems of different sizes and depths, for example (a) $b_{Z}$ $=2.5 \mathrm{~km}, Z_{0}=15 \mathrm{~km}$ and $(\mathbf{b}) b_{Z}=1 \mathrm{~km}, Z_{0}=10 \mathrm{~km}$.

Figure A1. Set up for numerical model in Appendix 1.

Figure A2. Numerical model results testing the validity of the scaling relationships described in Appendix 1. The dashed lines correspond to simple exponential decay curves with a timescale equal to $\tau_{R}, \tau_{b}, \bar{\tau}$ and $\tau_{0}$, respectively.

Figure A3.. Set up for model of mid-crustal pluton 'hidden' at depth in Appendix 2.

Figure A4. Laplace's analytical solution and the actual solution for a finite region are comparable except very close to the surface. 
(A) LAPLACE'S SOLUTION

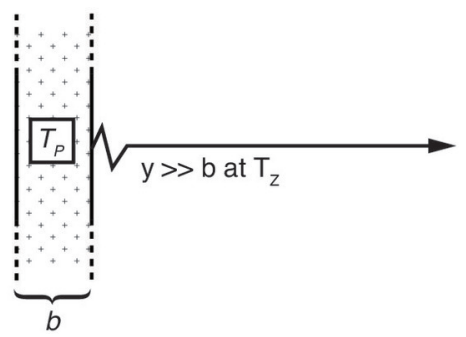

(C) SMALL TABULAR PLUTON

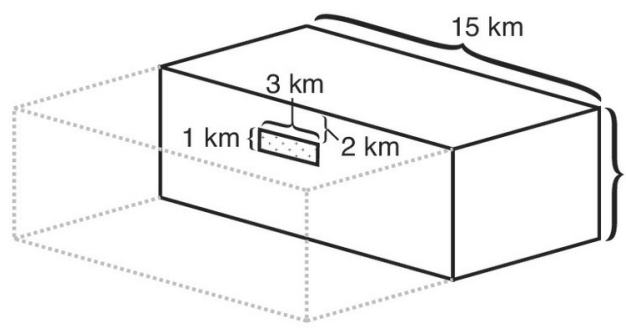

(D) LARGE TABULAR PLUTON

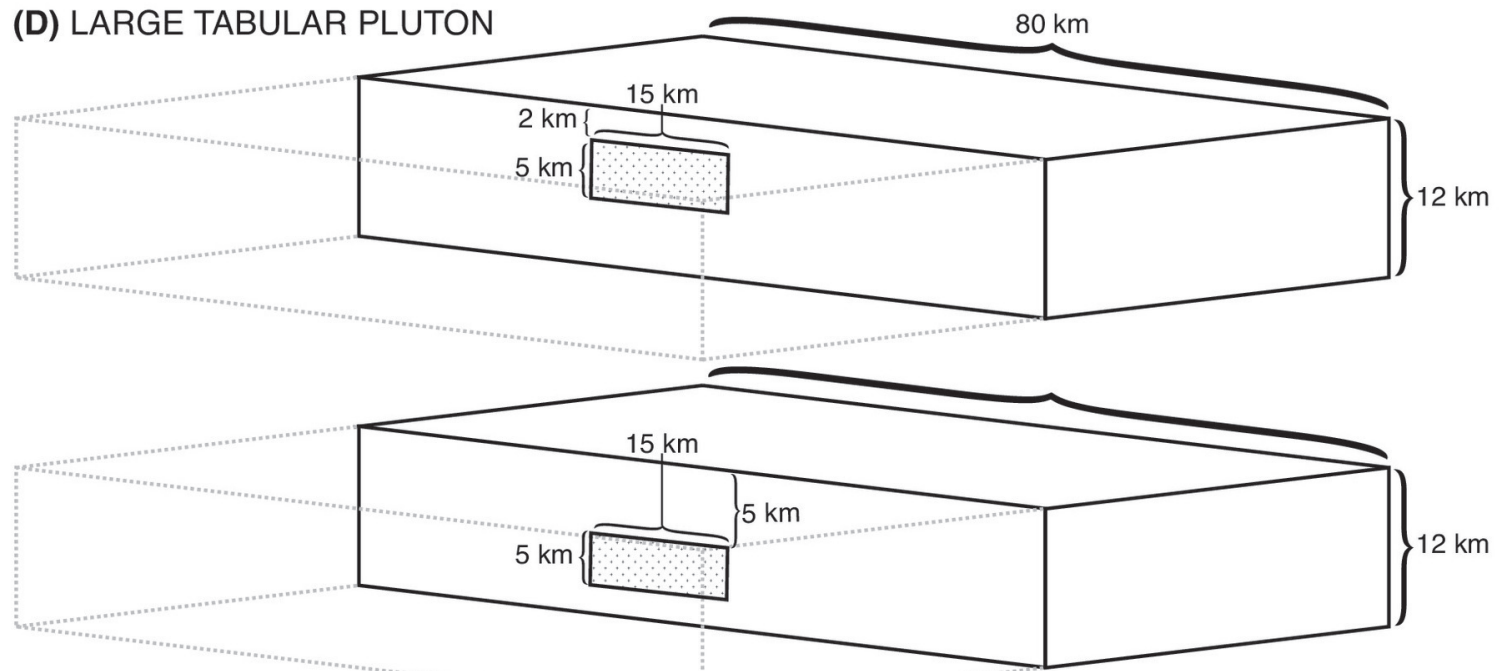

(E) MIDCRUSTAL TABULAR PLUTON
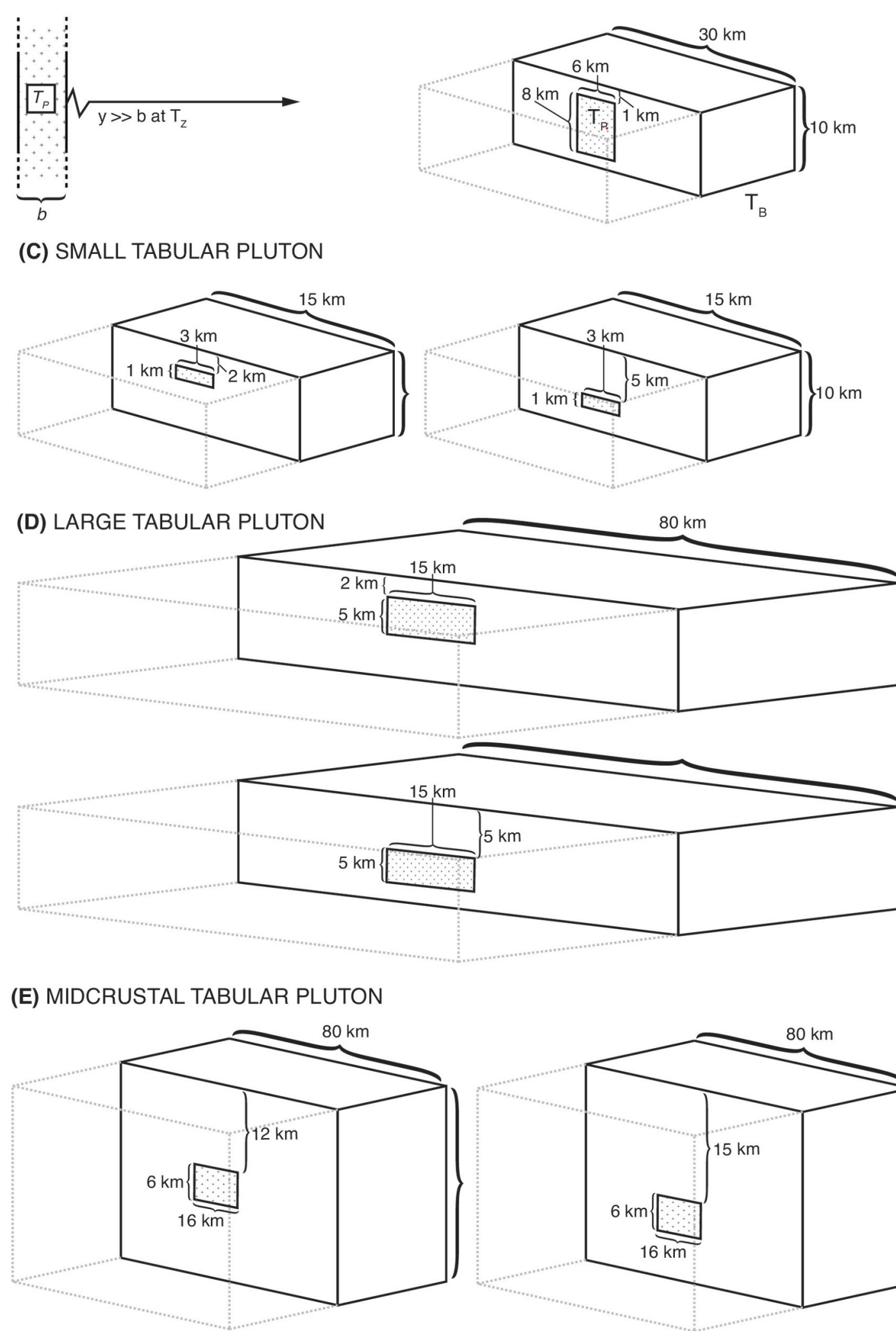
(A)

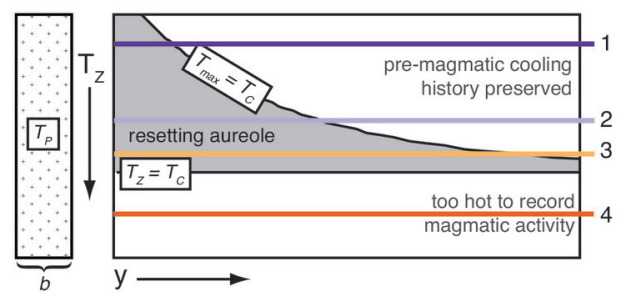

(B)
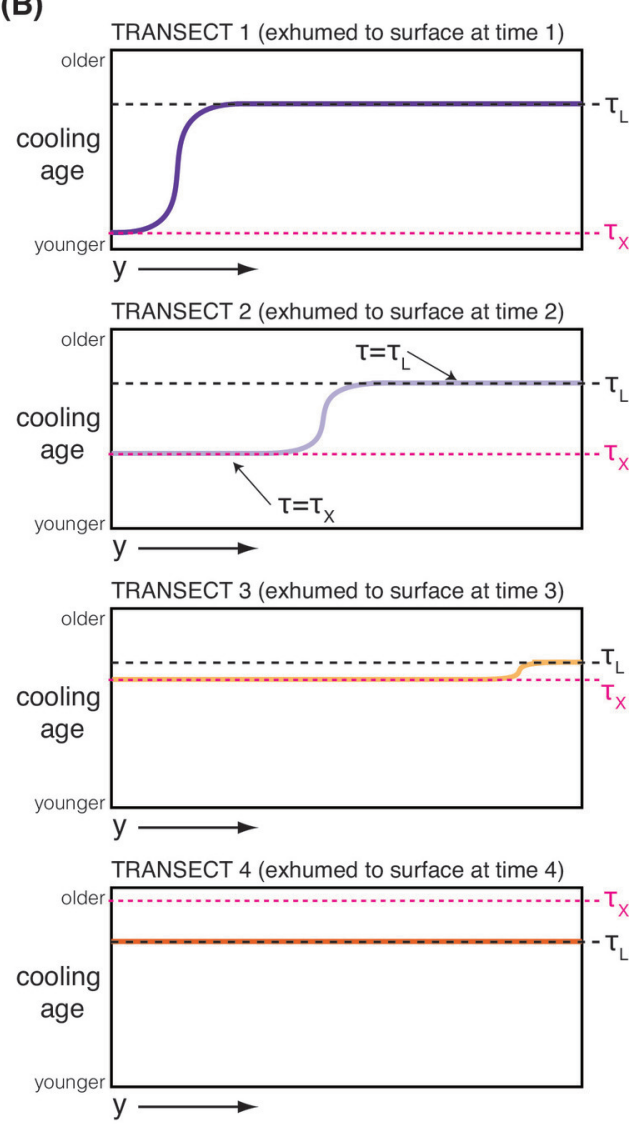

Murray et al., Figure 2

2018gc007595-f02-z-.eps

This article is protected by copyright. All rights reserved. 
(A) PREDICTED

RESETTING AUREOLES

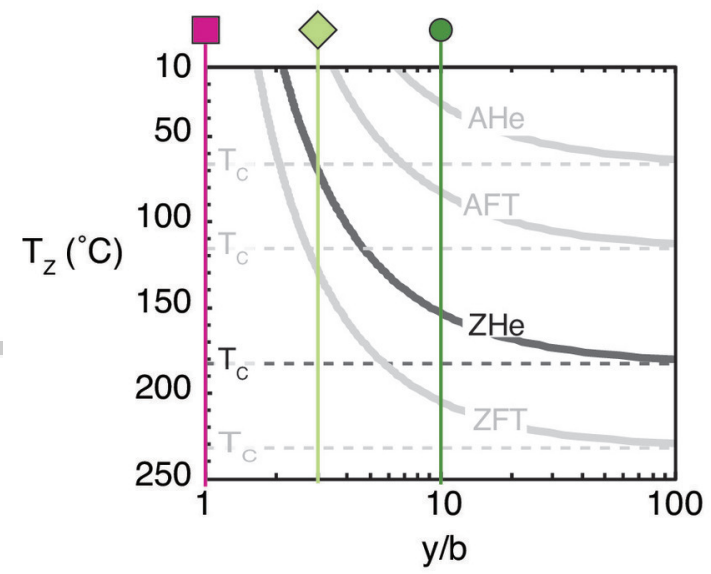

(B) AGE-T, RELATIONSHIP SET BY CONSTANT E

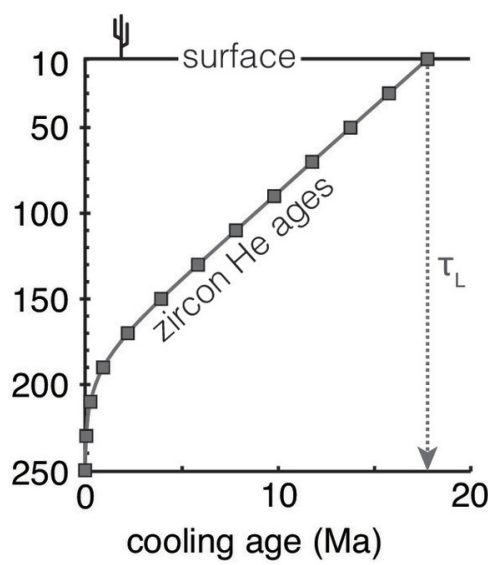

(C) PERTURBED AGE-T RELATIONSHIP

$\mathrm{t}_{0}$, immediately after pluton cooling

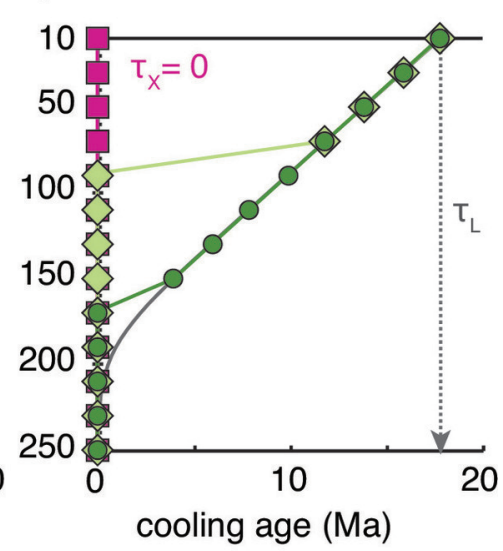

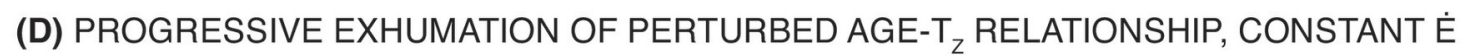
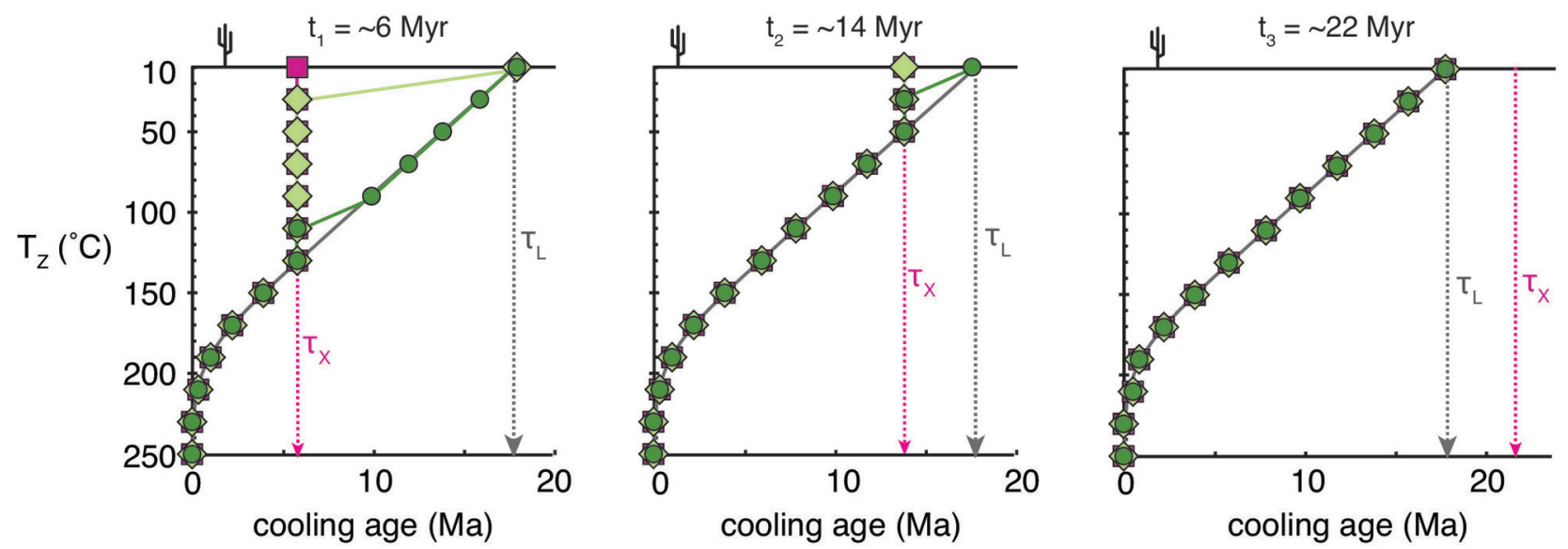

Murray et al., Figure 3 


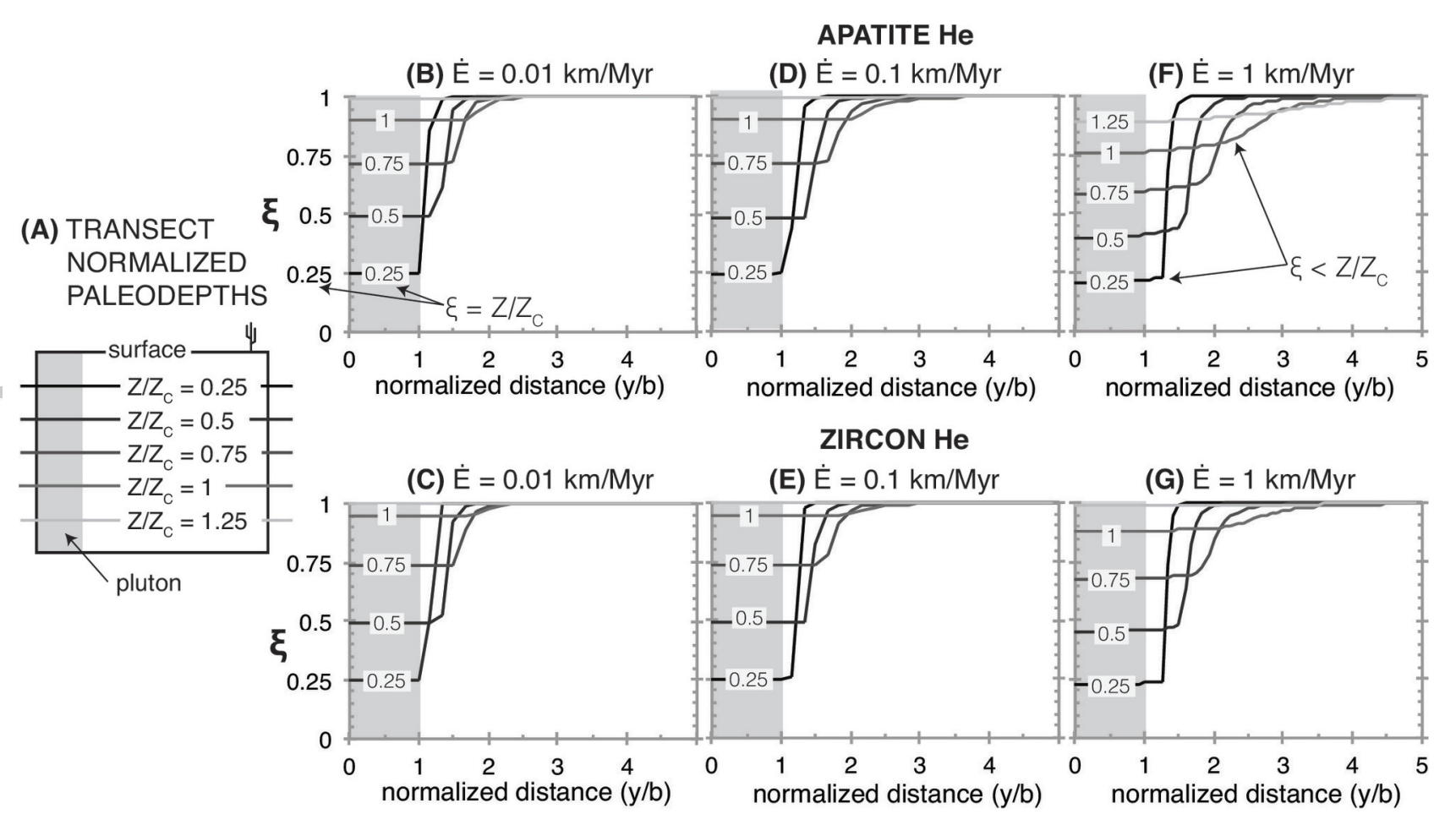

Murray et al., Figure 4 
(A) $P e=0.1$

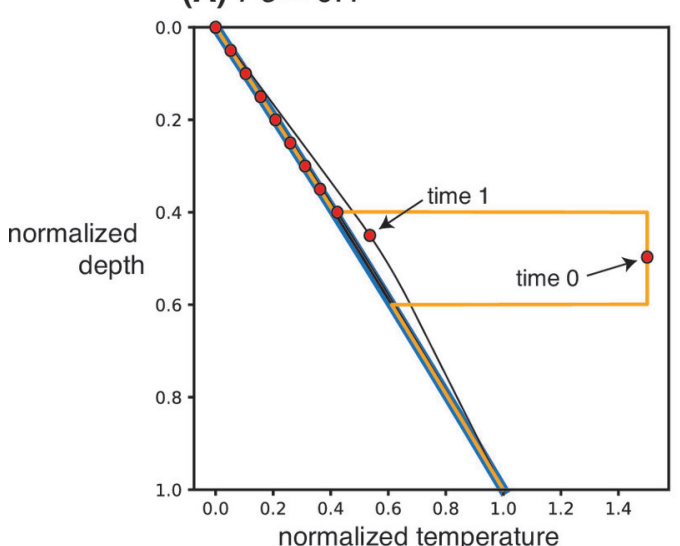

(B) $P e=1$

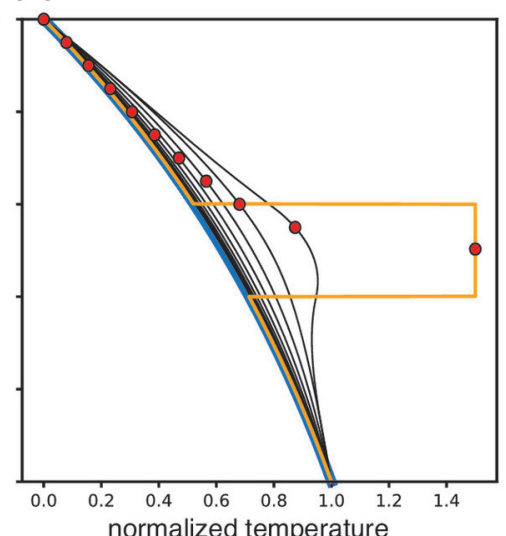

(C) $P e=10$

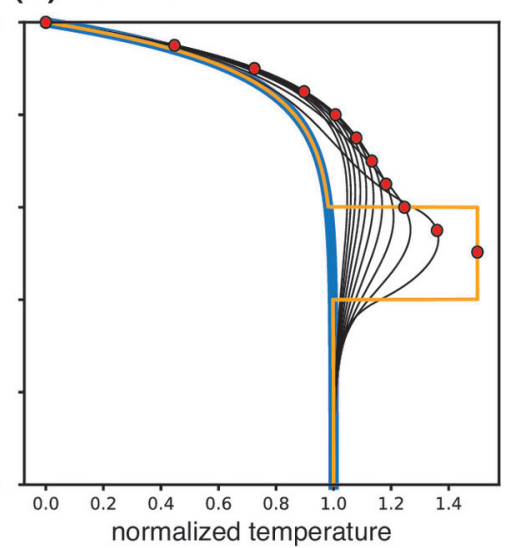

Murray et al., Figure 5 


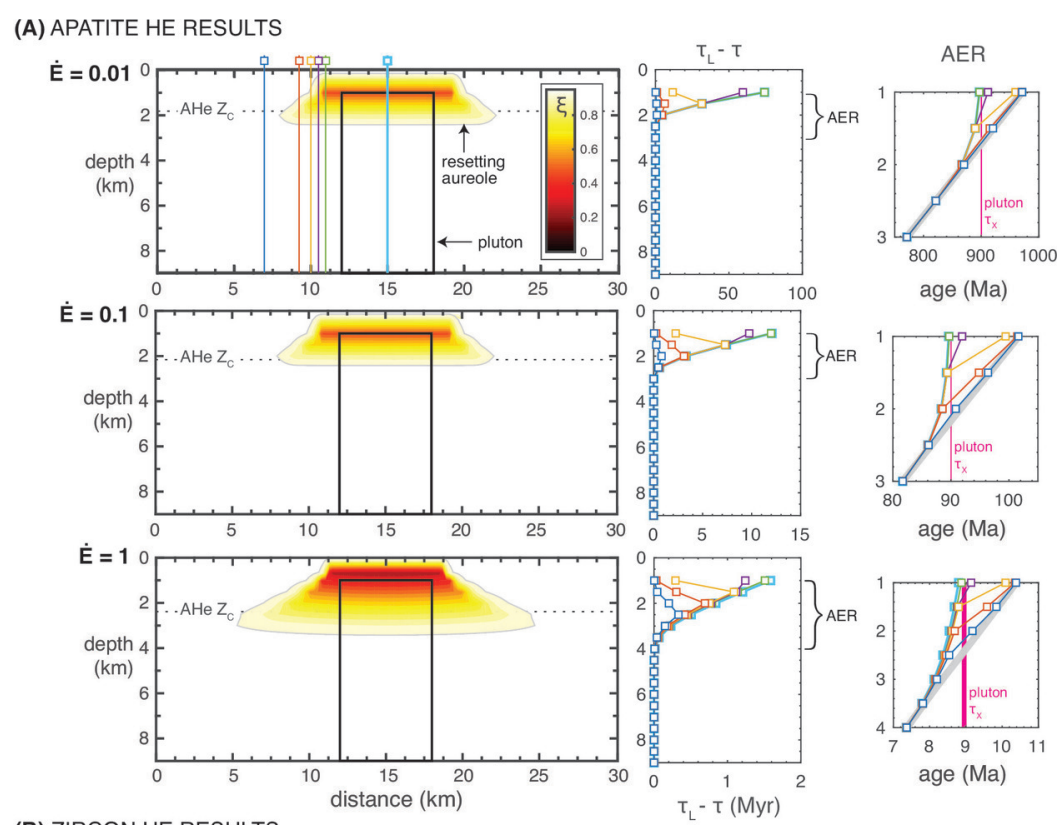

(B) ZIRCON HE RESULTS

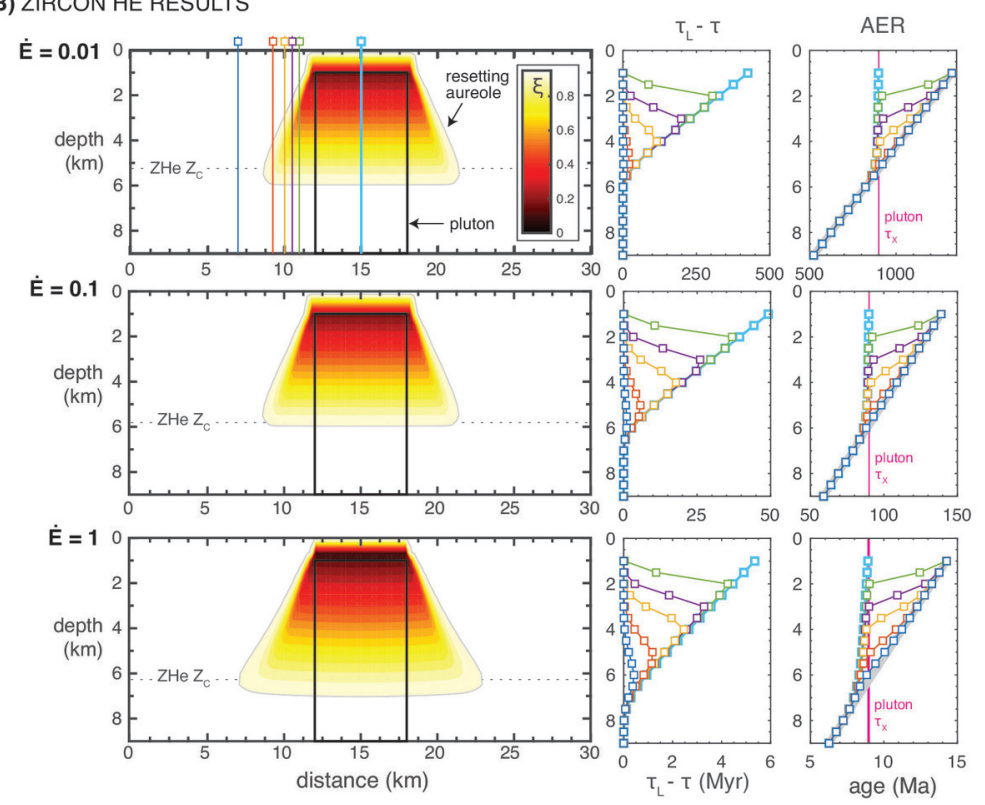

Murray et al., Figure 6

$$
\text { 2018gc007595-f06-z-.eps }
$$



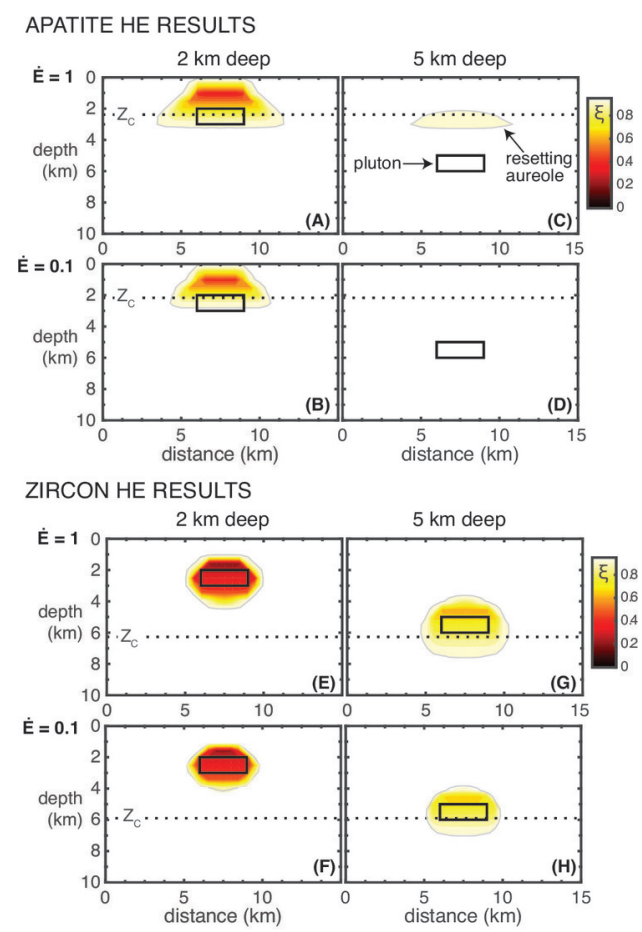

Murray et al., Figure 7

2018gc007595-f07-z-.eps

This article is protected by copyright. All rights reserved. 
APATITE HE RESULTS
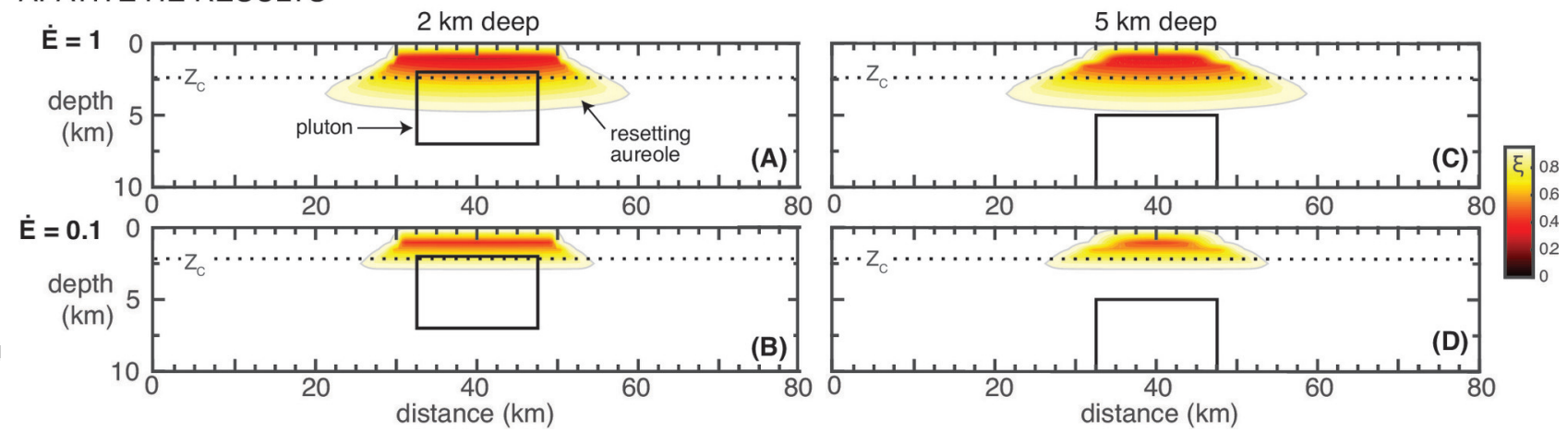

ZIRCON HE RESULTS
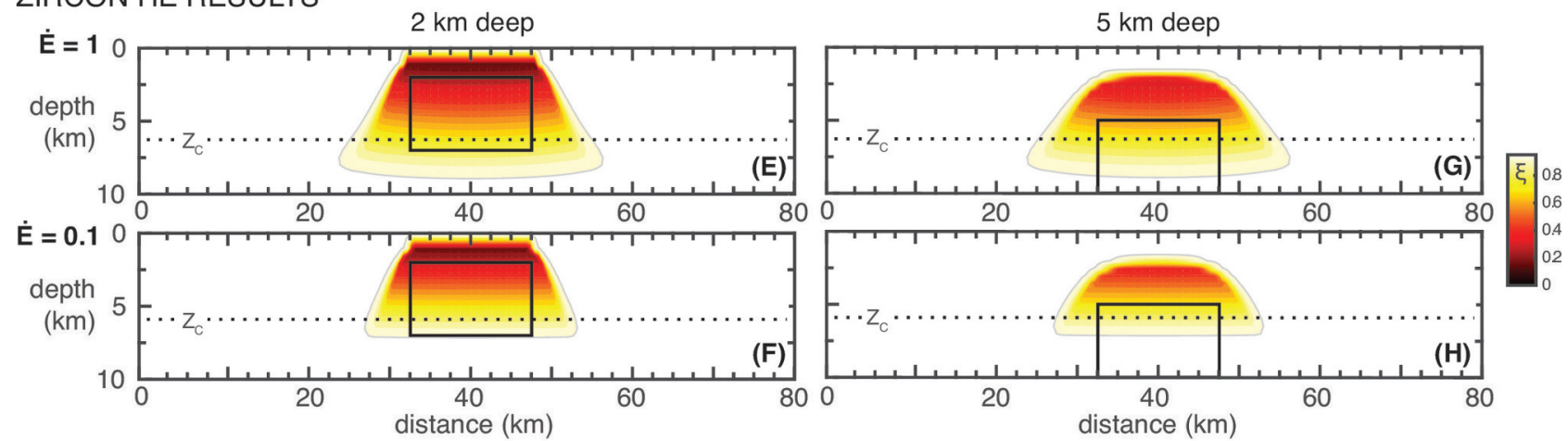

Murray et al., Figure 8 

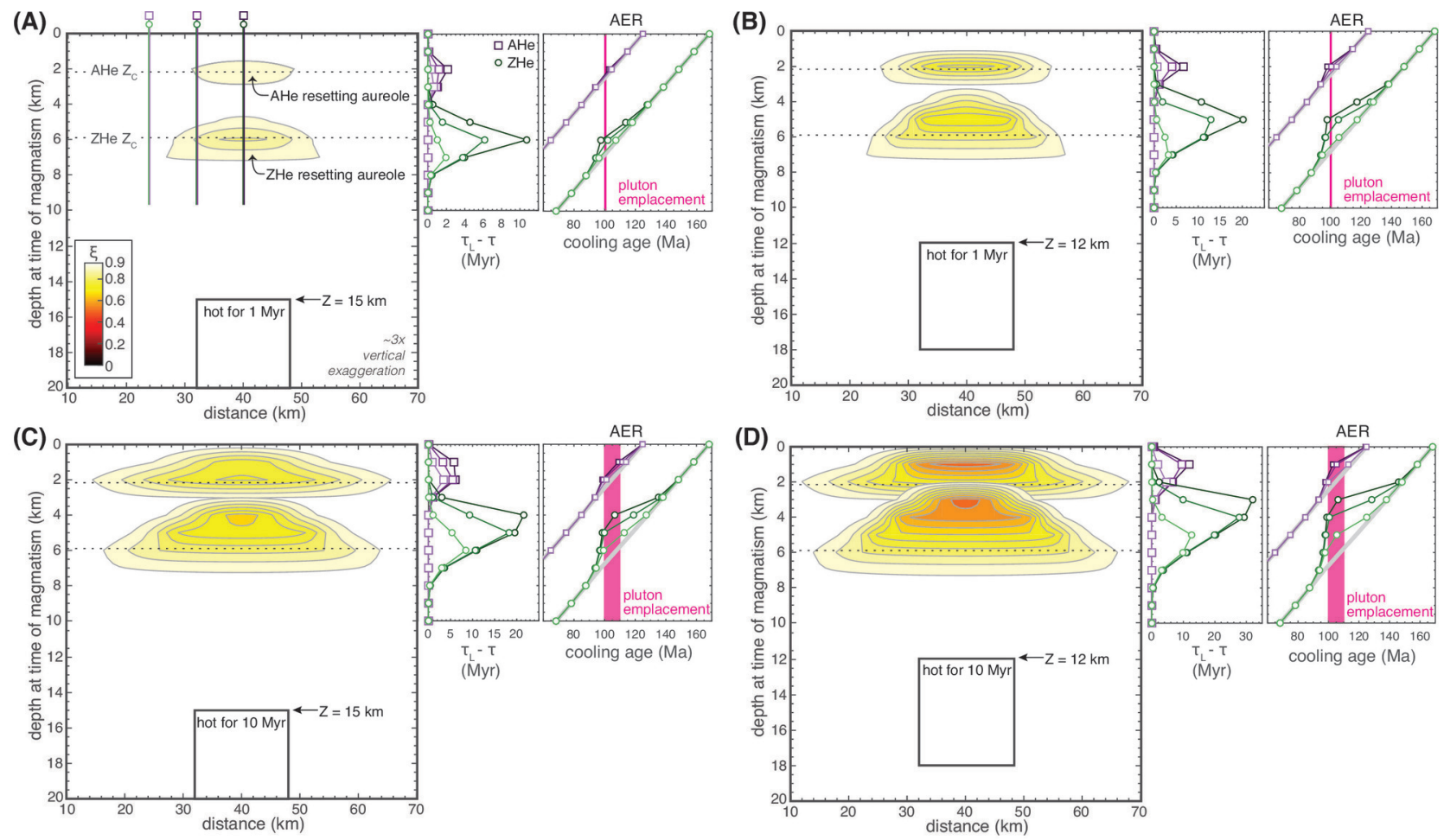

Murray et al., Figure 9 
(A) 5 KM THICK PLUTON AT 15 KM DEPTH

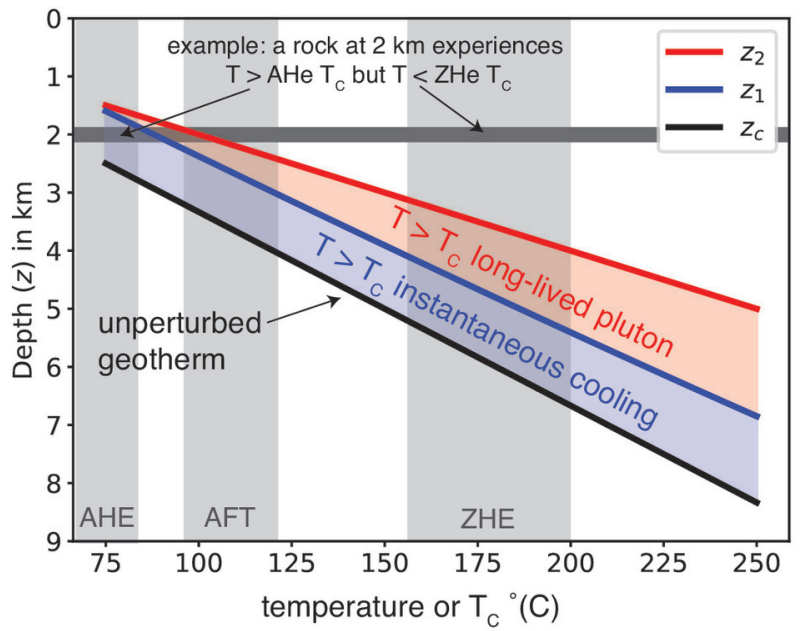

(B) 2 KM THICK PLUTON AT 10 KM DEPTH

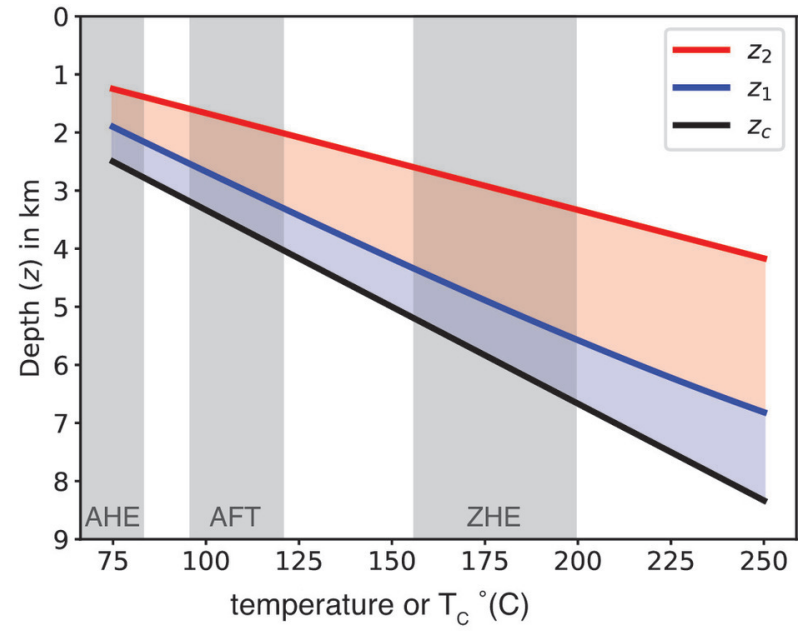

Murray et al., Figure 10

$$
\text { 2018gc007595-f10-z-.eps }
$$

This article is protected by copyright. All rights reserved. 


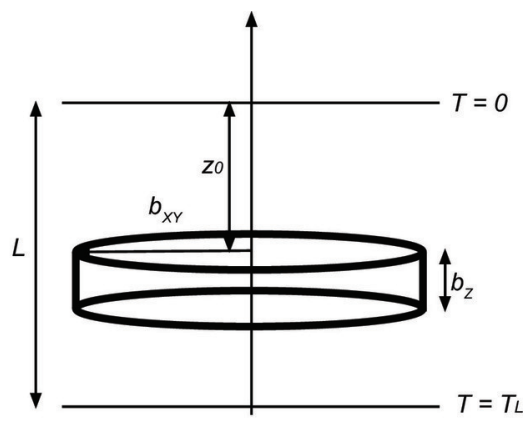

Murray et al., Figure A1

2018gc007595-f11-z-.eps

This article is protected by copyright. All rights reserved. 
Temperature at the center of the heat source

(A)

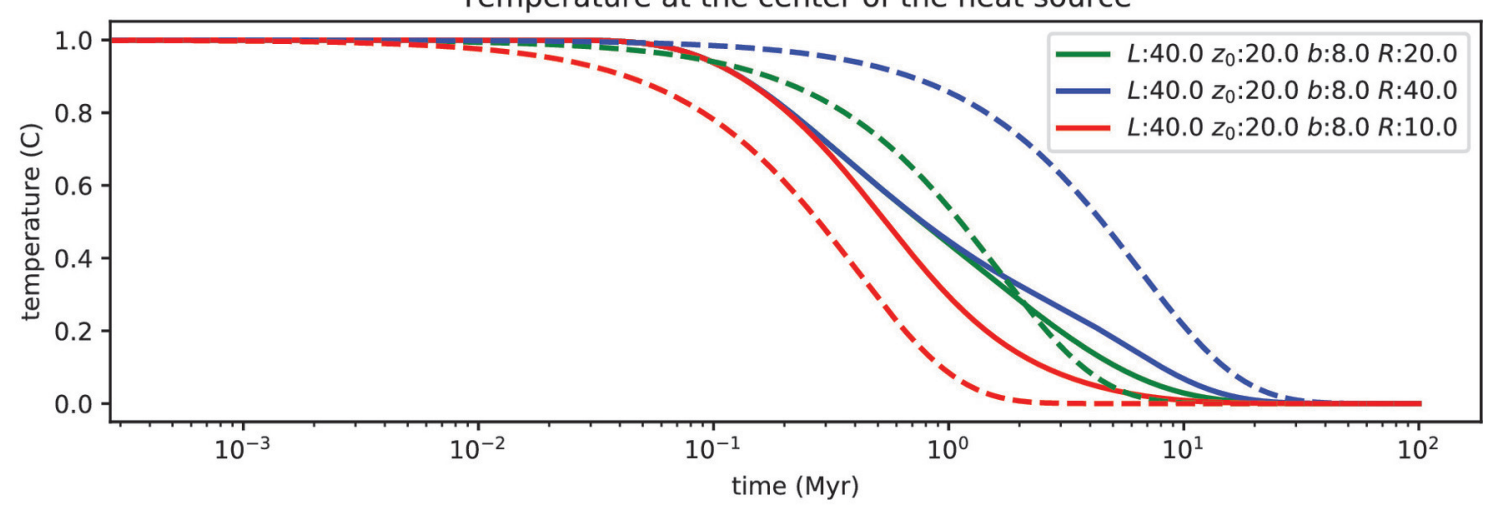

Temperature at the center of the heat source

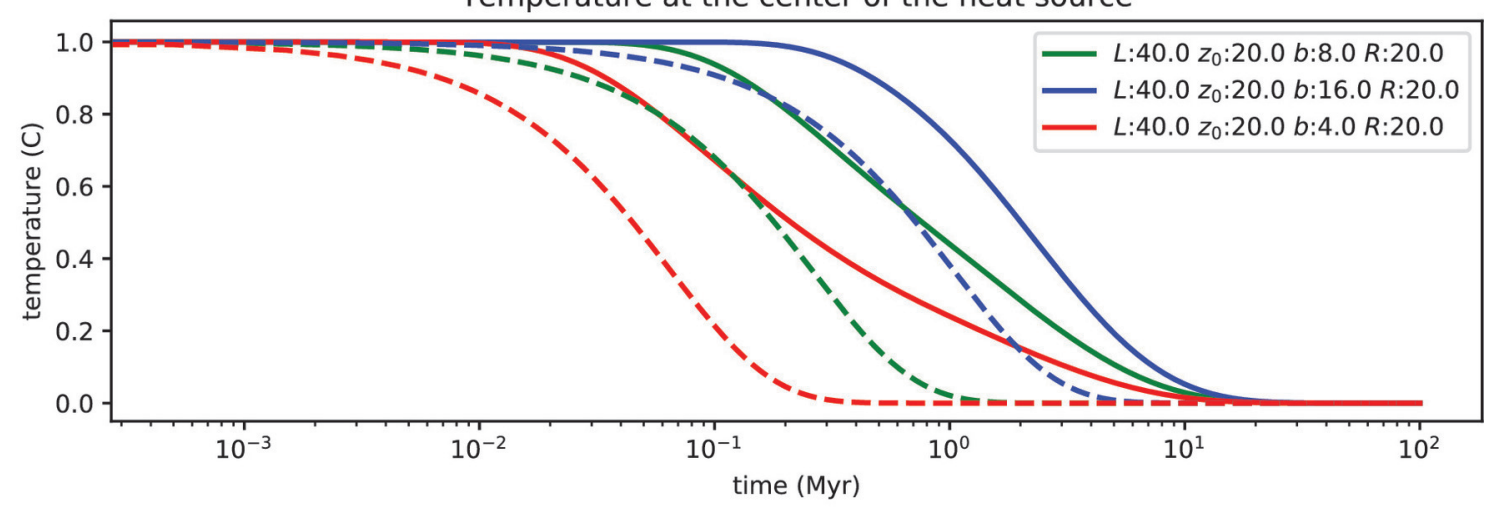

Temperature at the center of the heat source

(C)

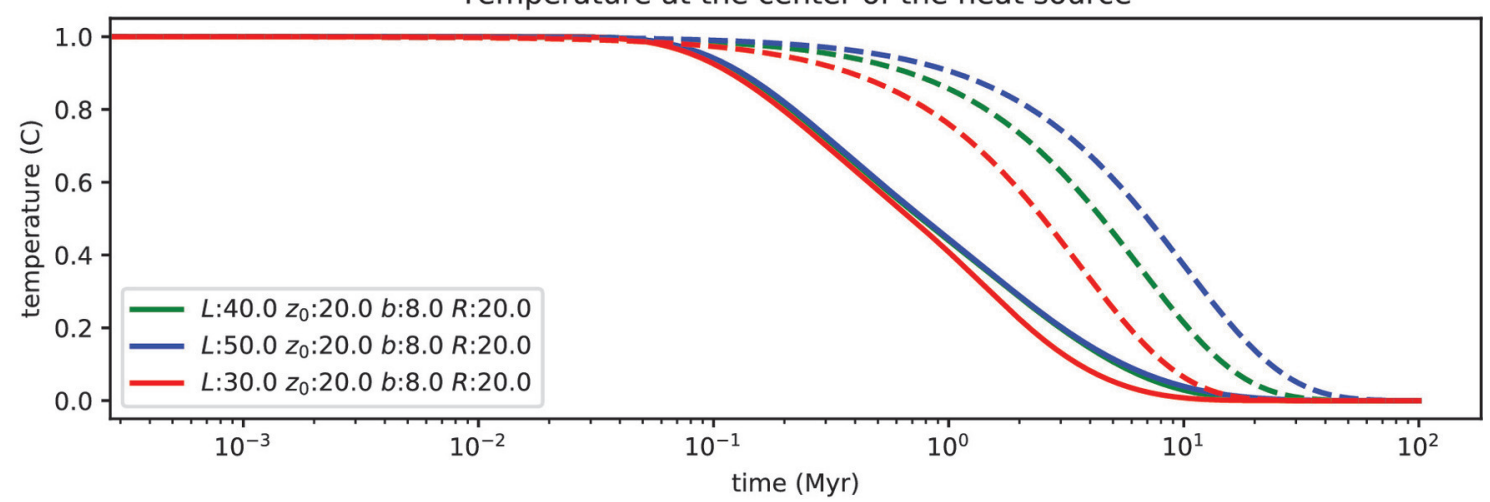

Temperature at the center of the heat source

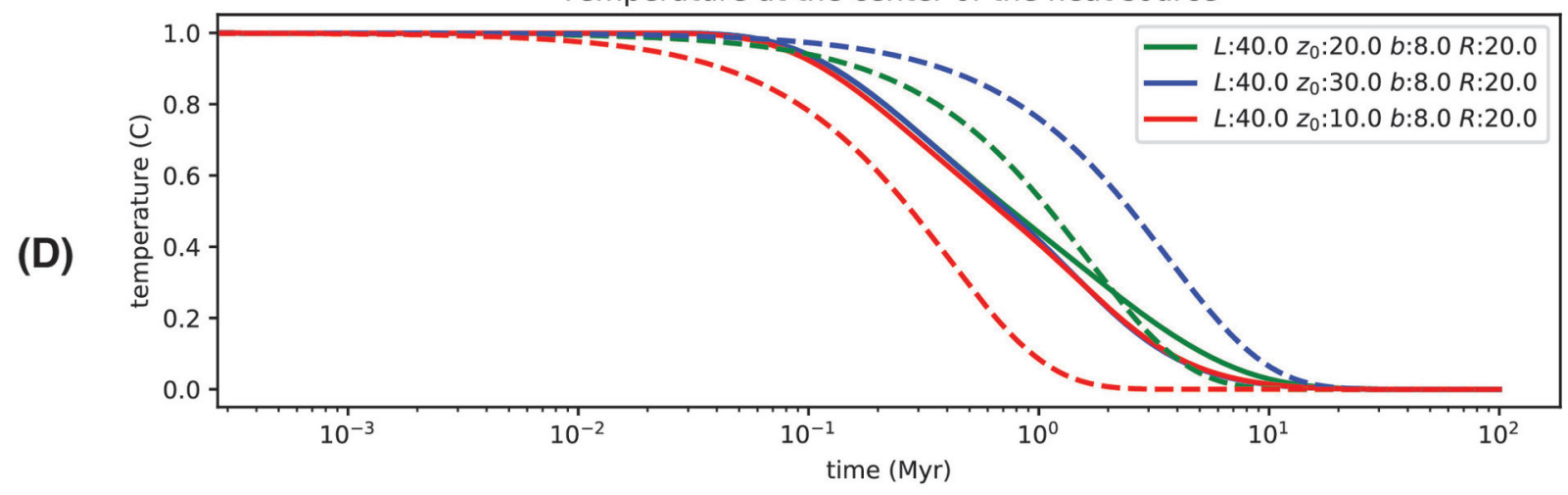

Murray et al., Figure A2 


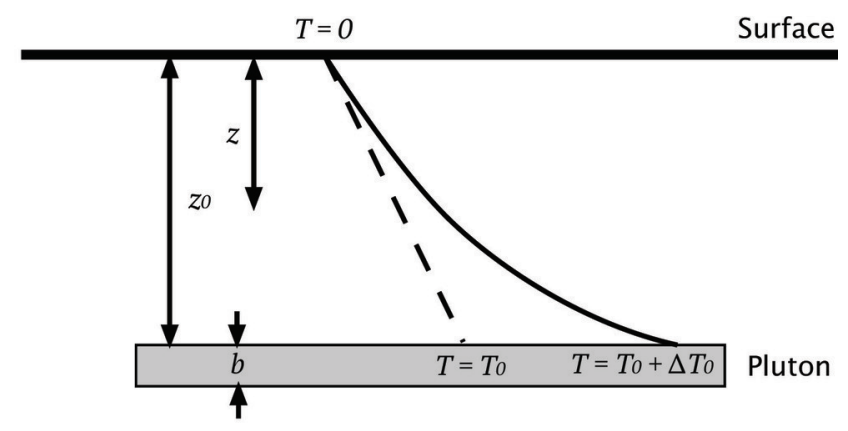

Murray et al., Figure A3

2018gc007595-f13-z-.eps

This article is protected by copyright. All rights reserved. 


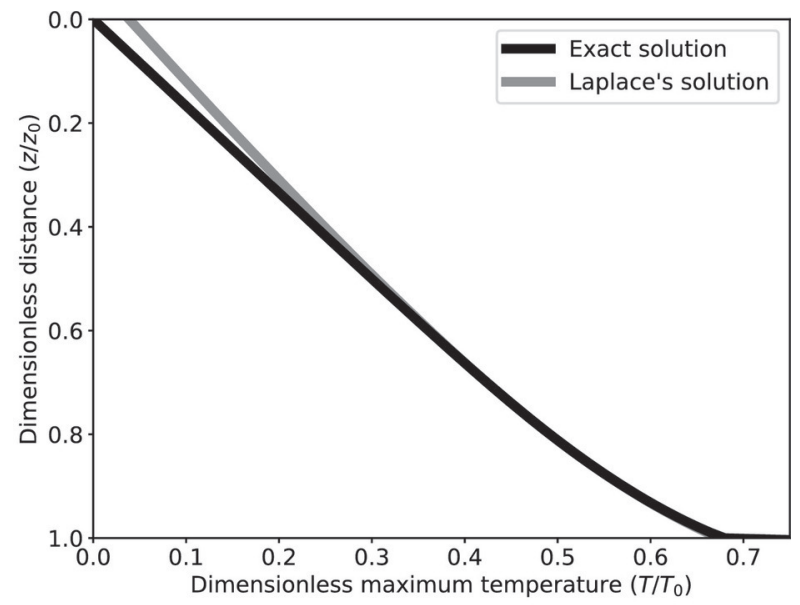

Murray et al., Figure A4

2018gc007595-f14-Z-.eps

This article is protected by copyright. All rights reserved. 